\title{
Roles for multifunctional and specialized spinal interneurons during motor pattern generation in tadpoles, zebrafish larvae, and turtles
}

\author{
Ari Berkowitz ${ }^{*}$, Alan Roberts ${ }^{2}$ and Stephen R. Soffe ${ }^{2}$ \\ 1 Department of Zoology, University of Oklahoma, Norman, OK, USA \\ 2 School of Biological Sciences, University of Bristol, Bristol, UK
}

\section{Edited by:}

William Kristan, University of California San Diego, USA

\section{Reviewed by:}

Joseph Fetcho, Cornell University, USA Dirk Bucher, University of Florida, USA

*Correspondence:

Ari Berkowitz, Department of Zoology, University of Oklahoma, 730 Van Vleet Oval, Norman, OK 73019, USA.

e-mail: ari@ou.edu
The hindbrain and spinal cord can produce multiple forms of locomotion, escape, and withdrawal behaviors and (in limbed vertebrates) site-specific scratching. Until recently, the prevailing view was that the same classes of central nervous system neurons generate multiple kinds of movements, either through reconfiguration of a single, shared network or through an increase in the number of neurons recruited within each class. The mechanisms involved in selecting and generating different motor patterns have recently been explored in detail in some nonmammalian, vertebrate model systems. Work on the hatchling Xenopus tadpole, the larval zebrafish, and the adult turtle has now revealed that distinct kinds of motor patterns are actually selected and generated by combinations of multifunctional and specialized spinal interneurons. Multifunctional interneurons may form a core, multipurpose circuit that generates elements of coordinated motor output utilized in multiple behaviors, such as left-right alternation. But, in addition, specialized spinal interneurons including separate glutamatergic and glycinergic classes are selectively activated during specific patterns: escape-withdrawal, swimming and struggling in tadpoles and zebrafish, and limb withdrawal and scratching in turtles. These specialized neurons can contribute by changing the way central pattern generator (CPG) activity is initiated and by altering CPG composition and operation. The combined use of multifunctional and specialized neurons is now established as a principle of organization across a range of vertebrates. Future research may reveal common patterns of multifunctionality and specialization among interneurons controlling diverse movements and whether similar mechanisms exist in higher-order brain circuits that select among a wider array of complex movements.

Keywords: behavioral choice, motor pattern selection, central pattern generation, spinal cord, interneuron, locomotion, escape

\section{INTRODUCTION}

Cellular and network mechanisms of behavioral choice or motor pattern selection are best understood for several invertebrate model systems containing a relatively small number of individually identifiable neurons (Morton and Chiel, 1994; Marder and Calabrese, 1996; Kupfermann and Weiss, 2001; Marder and Bucher, 2001; Marder et al., 2005; Katz and Hooper, 2007; Briggman and Kristan, 2008). In recent years, however, significant progress has also been made in understanding how the vertebrate hindbrain and spinal cord select among and generate multiple types of behaviors that involve the same muscles. The hindbrain and spinal cord, even without input from higher brain centers, can produce multiple forms of locomotion, escape and withdrawal behaviors, and (in limbed vertebrates) site-specific scratching. Mechanisms of motor pattern selection have been explored in some detail in the hindbrain and/or spinal cord of primarily three model systems: hatchling Xenopus tadpoles, larval zebrafish, and adult turtles. Studies on these model systems have focused on the motor patterns underlying short-latency escape or withdrawal responses and forward swimming in all three animals, struggling in tadpoles and zebrafish, and three forms of scratching in turtles.
Until several years ago, the predominant view in the literature was that the same classes of vertebrate central nervous system (CNS) neurons can generate multiple, distinct kinds of movements, through either a reconfiguration of a single, shared circuit or through an increase in the number of neurons recruited within each identifiable class of neurons (Jankowska et al., 1967; Berkinblit et al., 1978; Lundberg, 1979; Grillner, 1981, 1985; Robertson et al., 1985; Carter and Smith, 1986; Bekoff et al., 1987; Gelfand et al., 1988; Pearson, 1993; Soffe, 1993, 1996; Berkowitz and Stein, 1994b; Green and Soffe, 1996; Johnston and Bekoff, 1996; Svoboda and Fetcho, 1996; Earhart and Stein, 2000a; Juranek and Currie, 2000; Lieske et al., 2000; Marder, 2000; Berkowitz, 2001b; Marder and Bucher, 2001). For example, it was proposed in pioneering studies in the cat that a single spinal cord central pattern generator $(\mathrm{CPG})$ produces both scratching and walking motor patterns (Berkinblit et al., 1978). In addition, many brainstem neurons were shown to contribute to multiple forms of breathing and oromotor movements (Grelot et al., 1993; Oku et al., 1994; Gestreau et al., 1996, 2000, 2005; Lieske et al., 2000; Baekey et al., 2001; Shiba et al., 2007). Moreover, early data from the hatchling Xenopus tadpole suggested that the same classes of spinal cord interneurons produce swimming and a 
stronger struggling motor pattern, with a larger number of neurons being recruited from each class during struggling (Soffe, 1993, 1996; Green and Soffe, 1996). According to this view, the neuronal circuitry would be built around multifunctional neurons.

Certainly much of the data that emerged over several decades seemed to favor the idea of circuits based on multifunctional neurons. Evidence demonstrated that individual spinal interneurons are activated and fire during multiple kinds of spinal motor patterns (Berkinblit et al., 1978; Soffe, 1993; Berkowitz and Stein, 1994a,b; Berkowitz, 2001a,b, 2002, 2005, 2008; Berkowitz et al., 2006; Liao and Fetcho, 2008). This supported less direct evidence that the same spinal networks can generate or contribute to multiple behaviors (Jankowska et al., 1967; Robertson et al., 1985; Carter and Smith, 1986; Stein et al., 1986; Bekoff et al., 1987; Currie and Stein, 1989; Mortin and Stein, 1989; Green and Soffe, 1996; Johnston and Bekoff, 1996; Soffe, 1996; Svoboda and Fetcho, 1996; Juranek and Currie, 2000). Thus, the view became established that a single set of spinal cord interneuron types is sufficient to produce a wide variety of movements.

An alternative to such a multifunctional network is that each distinct type of sensory or descending supraspinal command excites a completely separate spinal cord network that is dedicated to producing just one behavior. In its simplest form, this alternative hypothesis is clearly inconsistent with the evidence outlined above. However, recent research in zebrafish larvae (Ritter et al., 2001) and subsequently in all three model systems (hatchling tadpoles, Li et al., 2007; zebrafish larvae, Ritter et al., 2001; Kimura et al., 2006; McLean et al., 2007, 2008; Liao and Fetcho, 2008; Satou et al., 2009; Wyart et al., 2009, and adult turtles, Berkowitz, 2002, 2007, 2008) has forced a change in the view of how a vertebrate CNS selects and generates different, coordinated motor patterns. These studies, which have examined motor patterns that operate using the same motoneurons and muscles, have demonstrated that in addition to spinal interneurons that are clearly multifunctional, there are others that are selectively activated during one or more specific kinds of motor pattern but are not activated, and may even be inhibited, during others. In all three of the vertebrate model systems we will consider here, it is now suggested that distinct motor patterns are selected and generated by a combination of multifunctional and behaviorally specialized interneurons. By taking a comparative approach to the circuitry underlying a range of motor patterns in these three species, we hope to identify common mechanisms through which a combination of multifunctional and specialized interneurons produces the appropriate behavior in each circumstance.

Before embarking on this comparative review, certain elements of our approach need to be outlined. Since this is primarily a review about spinal interneurons we need to consider briefly their identification and classification. We can start to address questions about multifunctionality versus specialization just by studying the activity of single interneurons during different motor patterns. However, as the ability to categorize neuronal types improves, these questions can start to be set in a broader functional context. In terms of neuron classification, the first principle is that spinal sensory information comes in dorsally and motor output exits ventrally. In general, anatomical and physiological evidence shows that sensory interneurons are located more dorsally and premotor interneurons more ventrally. This pattern of organization arises during development when longitudinal columns of precursor cells arranged in a defined dorsoventral sequence give rise to longitudinal columns of interneurons expressing distinctive transcription factors (Jessell, 2000; Goulding et al., 2002). Without functional information, spinal interneurons can be classified by their genetics, position (most fundamentally dorsoventral), dendritic fields, and axonal projections (ascending, descending, commissural). When we add the most basic functional factor, the neurotransmitter phenotype, interneurons can be placed into broad categories: sensory pathway excitatory interneurons (directly excited by sensory input, which they distribute), premotor excitatory interneurons (driving motoneuron activity), premotor recurrent inhibitory interneurons (that limit firing, like Renshaw cells), and premotor reciprocal inhibitory interneurons (between antagonists). There is not a rigid hierarchy: for example, sensory pathway interneurons can synapse directly onto motoneurons, in which case they are also premotor. However, even if these categories have exceptions, they are still useful. Thus, after reviewing the behavior we will adopt this broad distinction, looking first at premotor interneurons and then at sensory pathway interneurons.

To follow a course of increasing complexity, we will adopt a broadly ontogenetic rather than phylogenetic approach, and will start by outlining the state of knowledge in animals at the earliest stage of development of our three systems: the hatchling Xenopus tadpole ( 2-days post-fertilization). We will then consider the relatively more developed zebrafish larva ( $\sim 3$ - to 10 -days postfertilization), and lastly the adult turtle. Using these three systems, we will show how a combination of multifunctional and specialized neurons is used to select and generate different motor patterns and try to identify common themes.

\section{THE GENERATION OF MULTIPLE, DISTINCT BEHAVIORS}

Although it is not readily apparent in many medical textbooks, it has been known for more than a century that the spinal cord, even without input from the brain, can be made to produce a range of approximately normal movements including locomotion, scratching, and withdrawal (Hall, 1833; Paton, 1846; Bickel, 1897; Sherrington, 1906a,b, 1910a,b). Studies have focused mainly on the control of individual movements or motor patterns. Until relatively recently, less consideration has been given to the involvement of neurons in multiple motor patterns. However, it is clearly the norm that particular neuromuscular systems, whether controlling the trunk or limbs, produce not one but a range of distinct behavioral responses.

\section{HATCHLING XENOPUS TADPOLES}

Xenopus tadpoles have mainly been studied at a single stage of development when they are free-living but as simple as possible. This is just after they hatch when they are $\sim 2$-days postfertilization (at $22-24^{\circ} \mathrm{C}$ stage $37 / 38$ of Nieuwkoop and Faber, 1956). These are the simplest of the animals we are considering here. Three clear types of trunk movements are found in response to mechanical skin stimulation (see Figure 1 in Roberts et al., 2010) and corresponding fictive forms of all three can be elicited by electrical stimulation of the skin in tadpoles immobilized in $\alpha$-bungarotoxin. 
A gentle touch or stroke to the trunk or tail skin with a fine hair leads to a short-latency flexion response which is usually on the opposite side (Boothby and Roberts, 1995). Occasionally, this flexion occurs alone, but usually it is followed by swimming. The flexion response can be small or may be large enough to throw the body into a C-shape. This response bends the body away from touch, so is a form of withdrawal response, like the first part of the C-start response of the fish (see below).

In swimming, waves of bending alternate at frequencies from 10 to $25 \mathrm{~Hz}$, start in the rostral trunk, and spread to the tail, where the amplitude gets larger (Kahn et al., 1982). Frequency is highest immediately after stimulation and then tends to decrease gradually. However, it can stabilize and continue for many seconds or even minutes during the long swims that may occur if the tadpole does not contact an obstacle.

Struggling occurs when the tadpole is strongly stimulated, such as when it is grasped by a predator or when there is strong pressure to the skin anywhere on the body. In this case, after an initial, very strong C-flexion, waves of bending alternate at frequencies from 2 to $10 \mathrm{~Hz}$ and spread from the tail towards the head (Kahn and Roberts, 1982). If released from restraint, and therefore stimulation, there is a rapid transition from struggling back to swimming (Green and Soffe, 1996). Struggling in immobilized tadpoles can be evoked by repetitive electrical stimulation of the skin at $25-40 \mathrm{~Hz}$ (Soffe, 1991).

\section{LARVAL ZEBRAFISH}

Studies on motor responses in young zebrafish (Danio rerio) have spanned a range of developmental stages, from early embryos (Saint-Amant and Drapeau, 1998) through those broadly equivalent to the hatchling Xenopus tadpoles described above, to the somewhat more sophisticated (and complex) larvae we will consider here ( 3 - to 10-days post-fertilization; see Figure 1). Because of the rapid rate of early development, we will attempt to distinguish results from larvae of different ages. Overall, larval zebrafish in this age range can generate several distinct kinds of axial body bending movements, including escape, swimming of various forms, and struggling (Eaton et al., 1977b; Budick and O’Malley, 2000; Buss and Drapeau, 2001; Muller and van Leeuwen, 2004; Fetcho et al., 2008; Liao and Fetcho, 2008). By 5 days, they also start to use their pectoral fins during some forms of swimming (Thorsen et al., 2004), though these are not considered here.

A C-start escape (startle response) can be evoked by a tactile stimulus like a tap to one side of the head, and later by vibration, as well as by auditory and visual stimuli. These stimuli cause a short-latency, fast, large bend of the head away from the stimulus, followed by a return bend (Eaton et al., 1977a,b; Budick and O'Malley, 2000; Muller and van Leeuwen, 2004; Satou et al., 2009). The escape response (rapid bend and return bend) is often followed by swimming.

Forward swimming can occur spontaneously and can also be evoked independent of escape by sudden illumination of the head or mechanical stimulation of the tail. Initially after hatching ( days 2- to 3-post-fertilization), larvae swim spontaneously but infrequently, with rhythmic axial bends of up to $100 \mathrm{~Hz}$, lasting from a few seconds to a minute. This early swimming is replaced by day 4 by "beat-and-glide" swimming in which episodes consist of short periods of active swimming, lasting 200 ms, separated by glides of $\sim 400 \mathrm{~ms}$ (Buss and Drapeau, 2001). In this later form, which is typical during larval development (Buss and Drapeau, 2001), a distinction can be made between "slow swimming" involving primarily the tail and strong, fast, "burst swimming" involving the whole body and often associated with escapes (Budick and O'Malley, 2000). During swimming generally, bends propagate from head to tail and are largest toward the tail (Eaton et al., 1977b; Budick and O'Malley, 2000; Ritter et al., 2001; Muller and van Leeuwen, 2004). Faster swimming involves larger bends. Swimming that follows escape generally begins at high speed and with larger bends that peak further from the tail (compared to slow, spontaneous swimming) and then slows down (Budick and O'Malley, 2000; Ritter et al., 2001; McLean et al., 2007; Satou et al., 2009).

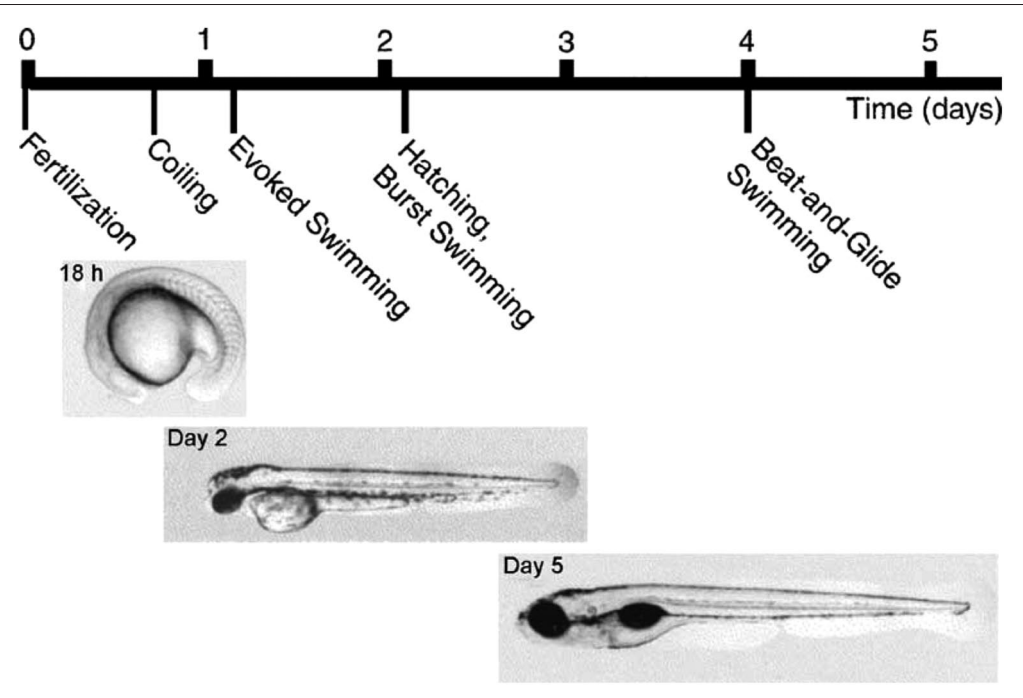

FIGURE 1 |The early development of behavior in the zebrafish. From Drapeau et al. (2002), used with permission of Elsevier. 
Struggling involves rhythmic waves of body bending that are larger than swimming, occur at about $20 \mathrm{~Hz}$, and propagate from tail to head (Liao and Fetcho, 2008). It can be elicited by pressure on the head (J. R. Fetcho, personal communication); this is similar to Xenopus tadpoles, in which struggling is elicited by an attempt to grasp the animal (Kahn and Roberts, 1982).

All of these behavioral motor responses can be elicited by electrical stimulation of the head. Typically, a single, strong pulse evokes escape, a single, weaker pulse evokes swimming (at a speed correlated with stimulus amplitude), and a series of still weaker pulses evokes struggling (Kimura et al., 2006; Liao and Fetcho, 2008). Each of these behaviors activates many of the same motoneurons, which in turn activate the same segmentally repeated muscles, in left-right alternation. As in the tadpole, corresponding fictive motor patterns underlying each of these behaviors can be evoked in immobilized animals (given a systemic neuromuscular blocking agent) using the same kinds of stimuli (Fetcho and O'Malley, 1995; Buss and Drapeau, 2001, 2002; Kimura et al., 2006; Bhatt et al., 2007; McLean et al., 2007; Liao and Fetcho, 2008; Satou et al., 2009). Swimming-like activity can be evoked in spinalized 3-day larvae by application of the glutamate agonist NMDA, indicating a spinal CPG (McDearmid and Drapeau, 2006). However, it seems likely that, as in the zebrafish embryo and the hatchling tadpole (Saint-Amant and Drapeau, 1998; Li et al., 2006), additional hindbrain circuitry is normally required to provide descending excitation and enable motor responses to be generated.

\section{ADULT TURTLES}

In obvious contrast to the two previous examples, the turtle is a limbed animal. Adult red-eared turtles (Trachemys scripta elegans) with a complete spinal cord transection just behind the forelimb enlargement can produce several distinct kinds of limb movements, even without input from the brain (Figure 2). These movements include limb withdrawal, forward and backward swimming, and three distinct forms of scratching (Lennard and Stein, 1977; Mortin et al., 1985; Earhart and Stein, 2000b; Stein, 2005). The turtle spinal cord thus provides an opportunity to investigate how the spinal cord selects and generates movements of a multi-jointed limb involving many kinds of muscles.

\section{Behaviors can be selectively evoked}

Limb withdrawal can be evoked by mechanical or electrical stimulation of the hindlimb skin (Stein et al., 1982). Forward swimming can be evoked by electrical stimulation of descending axons in the lateral funiculus of a mid-body spinal cord segment (Lennard and Stein, 1977). Scratching can be evoked by mechanical or electrical stimulation of the body surface (shell or skin) in an appropriate region (Valk-Fai and Crowe, 1978; Mortin et al., 1985). Rostral scratching is evoked by stimulation of the mid-body along the side of the animal. Pocket scratching is evoked by stimulation of the pocket region into which the animal withdraws its hindlimb. Caudal scratching is evoked by stimulation behind the hindlimb, near the tail. There are narrow transition zones between the rostral and pocket regions and between the pocket and caudal regions; stimulation in a transition zone can evoke either of the two scratch forms or a blend of the two (Mortin et al., 1985).

\section{Motor patterns are distinguishable}

Forward swimming, the three forms of scratching, and limb withdrawal all involve activation of the same set of limb motoneurons and muscles acting about the hip, knee and ankle. The relative

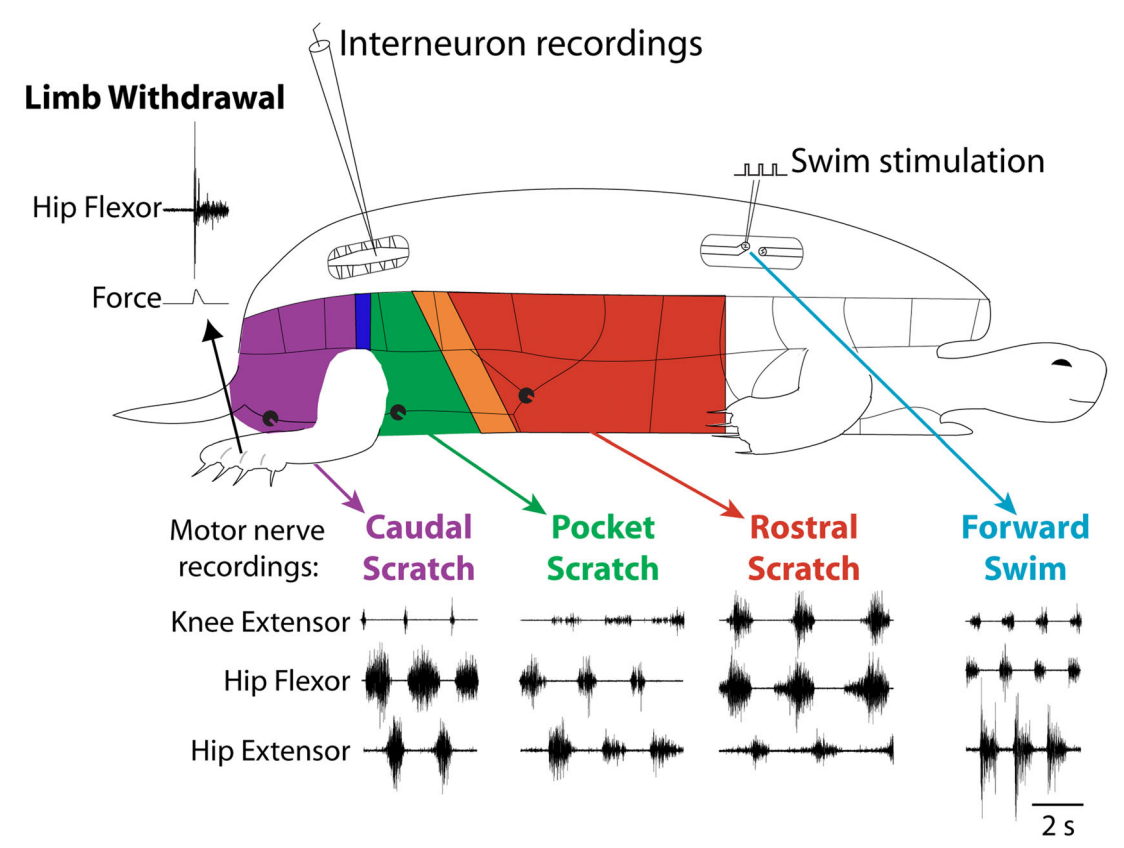

FIGURE 2 | Fictive motor patterns in hindlimb motor nerves evoked in an immobilized turtle with a spinal cord transection in vivo. Each of the three forms of scratching is elicited by mechanical stimulation of the shell or skin in the region indicated in color; stimulation in a transition zone between regions can elicit either of two forms or a blend of the two. Forward swimming is elicited by electrical stimulation in the contralateral lateral funiculus of a mid-body segment. Limb withdrawal is elicited by a tap to the dorsal foot. 
amplitudes and timing of activity in these motoneurons and muscles distinguish these behaviors from one another (Figure 2) (Lennard and Stein, 1977; Stein et al., 1982; Mortin et al., 1985; Robertson et al., 1985; Field and Stein, 1997; Earhart and Stein, 2000b; Juranek and Currie, 2000). Limb withdrawal is an episodic behavior involving a short-latency, strong, and gradually decrementing hip flexor burst, along with inhibition of knee extensors. Forward swimming and the three forms of scratching all involve repeated, rhythmic motor patterns with alternation between hip flexors and hip extensors. In forward swimming and caudal scratching, hip extension is the powerstroke and the hip extensor muscle or motor nerve burst is stronger and longer than the hip flexor burst. In rostral scratching, hip flexion is the powerstroke and the hip flexor burst is stronger and longer than the hip extensor burst. In scratching, knee extension produces the force against the body site that has been stimulated (i.e., the rub). The timing of the knee extensor burst within the cycle of hip flexor/hip extensor alternation determines which body site is rubbed and distinguishes the three forms of scratching from one another. The knee extensor burst occurs approximately in the second half of the hip flexor burst in rostral scratching, during the hip extensor burst in pocket scratching, and just after the hip extensor burst (and before the next hip flexor burst) in caudal scratching. In forward swimming, like rostral scratching, the knee extensor burst occurs in the latter portion of the hip flexor burst; in contrast to rostral scratching, however, the hip extensor bursts of forward swimming are longer and stronger than the hip flexor and knee extensor bursts.

\section{Fictive motor patterns}

Fictive motor patterns underlying limb withdrawal, forward swimming, and all three forms of scratching have been demonstrated by recording motor nerve activity in immobilized animals, using exactly the same stimuli that evoke the corresponding movements in animals with freely moving limbs (Figure 2) (Stein and Grossman, 1980; Stein et al., 1982; Robertson et al., 1985; Currie and Stein, 1989; Juranek and Currie, 2000). These motor nerve activity patterns are each very similar to the muscle activity patterns during the corresponding limb movements.

\section{ROLES FOR PREMOTOR INTERNEURONS IN THE GENERATION OF DISTINCT MOTOR PATTERNS}

In some invertebrate systems, motoneurons play significant roles in the shaping of rhythms and indeed in basic rhythm generation (Harris-Warrick et al., 1992). Although motoneurons can also contribute to shaping vertebrate motor output, generation and coordination of these motor patterns primarily results from the properties and interactions of premotor interneurons. With a few notable exceptions, defining these premotor neurons has remained a major obstacle to progress in understanding spinal cord motor control. For the model systems we are considering here, premotor interneurons are well defined in the tadpole and becoming so in the zebrafish. Although such confident definitions are not yet possible in the turtle, recordings from behaviorally specialized and rhythmically active interneurons in all three animals collectively undermine the view that vertebrate motor circuits are entirely multifunctional.

\section{TADPOLE PREMOTOR INTERNEURONS}

At its early stage of development, around 2-days post-fertilization, the hatchling Xenopus tadpole spinal cord contains only 10 types of neuron, arranged as loosely organized columns on the two sides of the CNS (Roberts, 2000; Perrins et al., 2002; Li et al., 2007; see also Roberts et al., 2010). Importantly, most of these columns of neurons extend from the spinal cord into the caudal hindbrain, so in what follows, descriptions of spinal neuron properties apply equally to neurons of the same types within the caudal hindbrain. Current evidence suggests that there is only a single population of motoneurons, which produces flexion, swimming, and struggling movements (Roberts et al., 1999). Of the 10 spinal neuron types, only four types are premotor interneurons. These fall readily into two groups. Two types of premotor interneuron are multifunctional and both of these are inhibitory. The other two types of premotor interneuron are specialized and both of these are excitatory.

\section{Multifunctional tadpole inhibitory interneurons}

Probably the most numerous of the tadpole spinal cord neuron types, the commissural interneurons (cINs) provide reciprocal inhibition between the two, antagonistic sides of the CNS (Dale and Roberts, 1985). Morphologically, these unipolar neurons have an axon that crosses to the opposite side of the spinal cord where it T-branches to produce ascending and descending projections over several segments (Roberts and Clarke, 1982; Soffe et al., 1984). The cINs are glycinergic, producing conventional, fast IPSPs in motoneurons and in all premotor interneuron types on the opposite side, but typically not in the more dorsally located sensory pathway interneurons. Many cINs fire impulses during swimming and struggling (Li et al., 2007) (Figure 3A). Like other swimming circuit neurons, cINs usually fire once per cycle. During struggling, they fire rhythmic bursts of impulses at up to $\sim 150 \mathrm{~Hz}$. These differences in firing appear to be simply a consequence of the underlying rhythmic excitation that drives firing on each cycle. Each cIN can fire repetitively when held depolarized by the strong rhythmic excitation during struggling. In contrast, the strong, brief excitation on each swimming cycle ensures that cINs fire only once.

A second group of inhibitory neurons, the recurrent inhibitory ascending interneurons (aINs), are also glycinergic and are also multifunctional. Morphologically, these neurons have an ascending axon on the same side of the CNS which characteristically branches just rostral to the soma to give a secondary descending projection (Li et al., 2002, 2004a). Like the cINs, aINs produce fast IPSPs in motoneurons and premotor interneurons but on the same side of the CNS. They also inhibit sensory pathway interneurons, and this, as described below, is of great significance for motor pattern selection. The aINs, like cINs, can fire repetitively so that, here too, different patterns of underlying excitation ensure that aINs usually fire once per cycle during swimming (though usually a little later than other neurons) but fire strong bursts of impulses during struggling (Li et al., 2007) (Figure 3B).

As populations, cINs and aINs are clearly multifunctional and so provide core functions of reciprocal and recurrent inhibition during swimming and struggling. However, some individual cINs and aINs only fire sporadically during swimming or when it is fast 


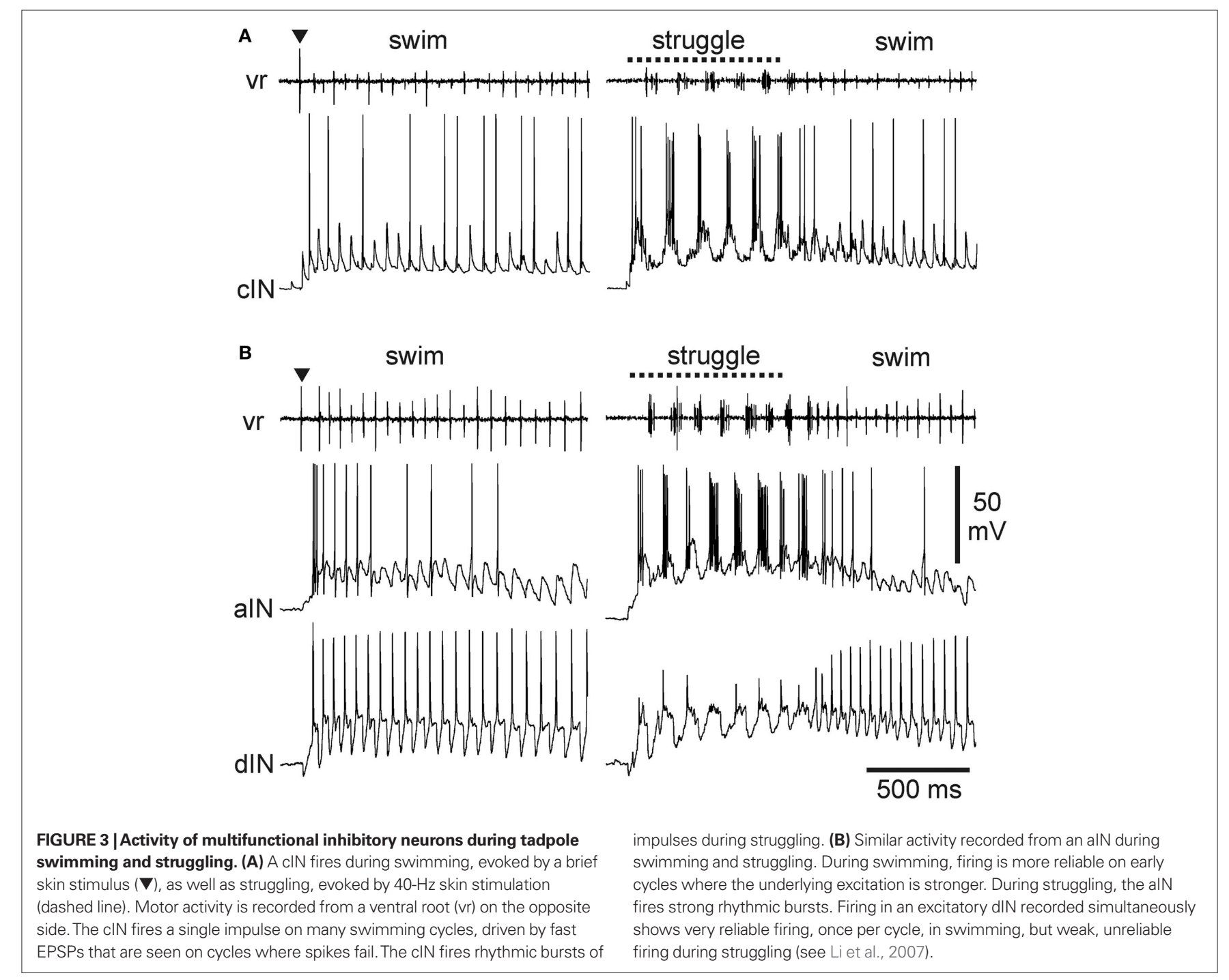

and the underlying excitation is relatively strong at the start of an episode (Figure 3). These same neurons are then recruited to fire strongly during struggling. In this sense, there are signs of specialization even within otherwise multifunctional groups.

\section{Specialized tadpole excitatory interneurons}

There is now compelling evidence identifying the descending interneurons ( $\mathrm{dINs}$ ) as the premotor interneurons that provide the principal rhythmic excitatory drive to spinal motoneurons and other premotor interneurons during swimming (Li et al., 2006; Soffe et al., 2009). They are multipolar neurons with a characteristic ipsilateral descending axon (Roberts and Clarke, 1982; Roberts, 2000). On each side of the caudal hindbrain and spinal cord, dINs fire reliably and first on each cycle, providing glutamatergic/cholinergic excitation to all swimming circuit neurons, including each other (Li et al., 2004c, 2006; Soffe et al., 2009). Their mutual chemical and electrical interactions provide a key element of the drive that maintains sustained swimming (Li et al., 2009). Given this key role in swimming, it seems at first surprising that dINs fire only weakly or not at all during struggling (Li et al., 2007) (Figures 3B and 4A).

Instead, during struggling, premotor excitation within each side of the CNS is provided by a different neuron type: the repetitive-firing dINs (dINrs) (Li et al., 2007). The similarity between names for these two types reflects the fact that morphologically they are largely indistinguishable; one difference is that some hindbrain dINs have additional ascending axons while dINrs do not. However, they differ significantly in their physiology.

The properties of dINs appear to make them specialized for driving swimming. They typically fire only once when held depolarized (Li et al., 2006) (Figure 4C). This property allows dINs to fire once on each swimming cycle (Figures $3 \mathrm{~B}$ and $4 \mathrm{~A}$ ) and as a consequence produce the brief, fast excitation that drives single impulses in other swimming circuit neurons. Firing of dINs on subsequent swimming cycles (the basis for swimming rhythm generation) depends in part on post-inhibitory rebound from cIN reciprocal inhibition (Soffe et al., 2009). The specialized physiology of dINs prevents them from firing bursts of impulses and therefore playing a significant role during struggling. In contrast, dINrs fire repetitively when held depolarized and fire bursts of impulses during struggling (Figures $4 \mathrm{~B}, \mathrm{C}$ ). The particular properties of dINs may prevent 


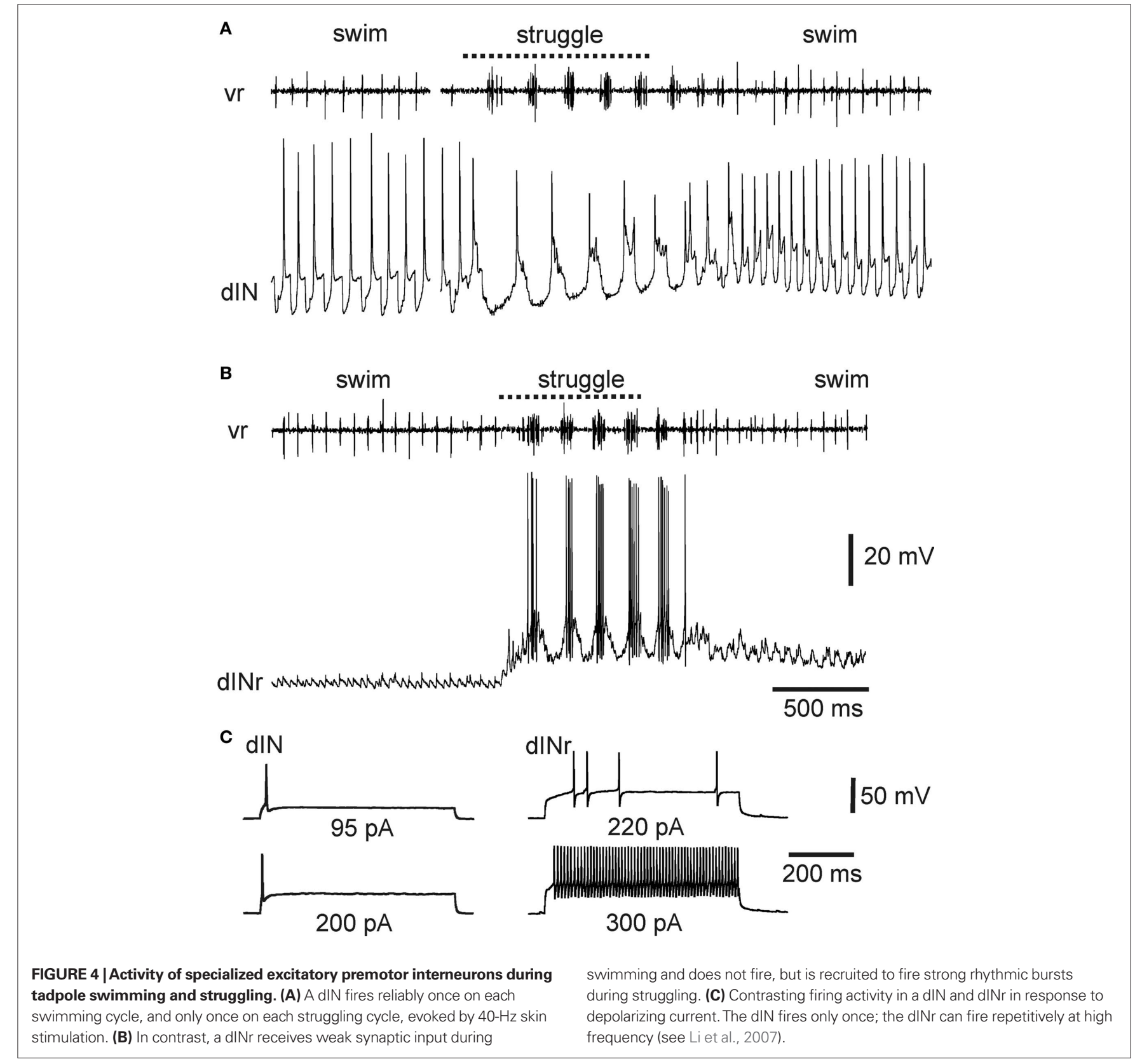

them from contributing significantly to struggling, but why do dINrs not contribute to swimming? One reason is that dINrs only receive relatively weak rhythmic excitation during swimming, so few of them fire (Figure 4B).

\section{ZEBRAFISH LARVAL PREMOTOR INTERNEURONS}

Following a pioneering study by Bernhardt et al. (1990), the morphological types of neurons in the spinal cord of the early developing zebrafish have been studied extensively using a variety of techniques (Bernhardt et al., 1990; Hale et al., 2001; Higashijima et al., 2004c). The relatively small number of interneurons $(\sim 7)$ distinguished morphologically by the end of day 1 roughly doubles over the next few days of the start of larval life. A recent review lists 14 neuron types, although the exact age is not specified (Goulding,
2009). Here, we will focus on those that have been shown to be activated during escape, swimming, and struggling during the period of early larval life ( $\sim 3$ - to 5 -days post-fertilization).

\section{Multifunctional and specialized inhibitory interneurons in zebrafish larvae}

At 3-days post-fertilization (broadly equivalent to the hatchling tadpole), the zebrafish spinal cord contains several types of glycinergic inhibitory interneuron (Higashijima et al., 2004a,c; Liao and Fetcho, 2008). These are involved to different extents in the main motor responses. One type, commissural bifurcating longitudinal interneurons (CoBLs), is clearly multifunctional (Liao and Fetcho, 2008). These have a commissural axon, which T-branches and projects rostrally and caudally on the opposite side. CoBLs are 
probably homologous to the tadpole cINs, which mediate the main reciprocal inhibition between antagonistic motor systems on the two sides. Most CoBLs fire during swimming and struggling, with just a few firing during escape.

In contrast to the multifunctional, inhibitory CoBLs, other glycinergic neurons in the 3-day zebrafish are clearly specialized (Liao and Fetcho, 2008). Commissural longitudinal ascending interneurons (CoLAs) also have a crossing axon that branches on the opposite side but with its main projection rostral. CoLAs are highly specialized: they fire strongly during struggling but do not fire at all during escape or swimming (Figure 5). Their morphology shows that they are likely to mediate a primarily crossed, ascending inhibition but their function is currently unknown. Liao and Fetcho (2008) suggest that CoLAs may alter an excitability gradient along the spinal cord so that the propagation of motor activity, normally head-to-tail during swimming, is reversed to the tail-tohead propagation that is characteristic of struggling in both the larval zebrafish and hatchling tadpole (Kahn and Roberts, 1982; Soffe, 1991; Liao and Fetcho, 2008). A second highly specialized inhibitory interneuron type is commissural local interneurons (CoLos). CoLos have relatively short ascending and descending commissural projections and fire exclusively during escape. They have now been shown to have a very particular relationship with the Mauthner neurons that mediate escape responses in larval zebrafish (Satou et al., 2009). A similar relationship was previously shown for what may be the same commissural neurons in adult goldfish (Fetcho, 1990). CoLos are excited by the Mauthner axon via electrotonic synapses and, by directly inhibiting motoneurons on the opposite side, they can play a central role in ensuring the strictly contralateral nature of escape bends.

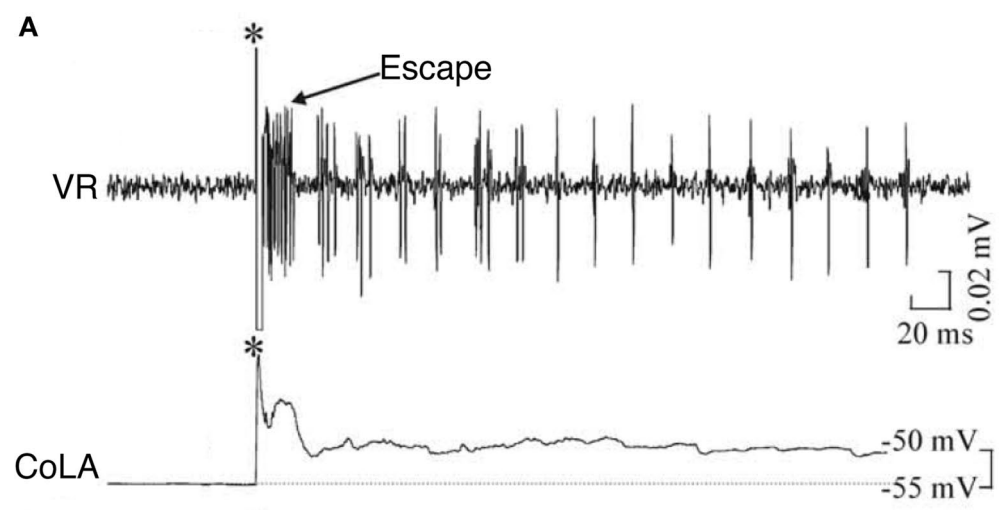

B

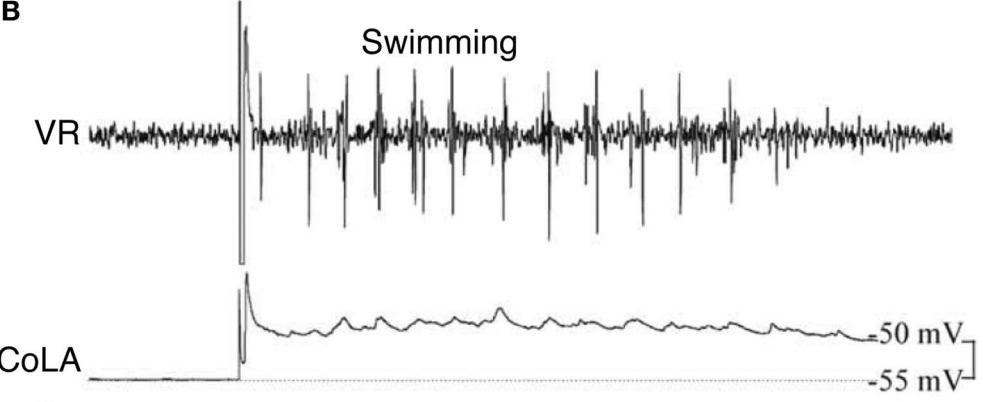

C

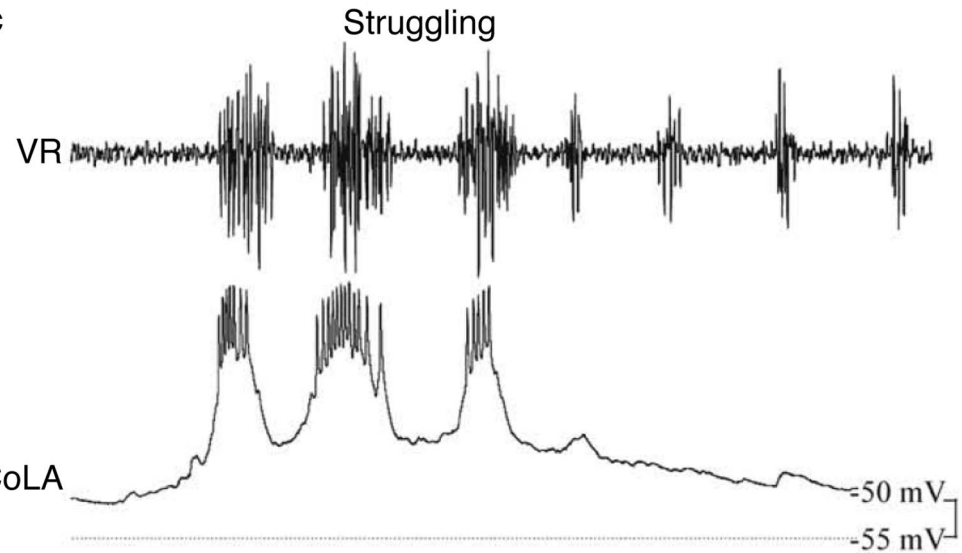

FIGURE 5 | Example of a zebrafish commissural longitudinal ascending interneuron (CoLA), not firing during (A) escape or (B) swimming, but firing strongly during (C) struggling. *, stimulus; VR, ventral root. Adapted from Liao and Fetcho (2008), with permission of the Society for Neuroscience. 


\section{Specialization of interneurons within motor patterns in zebrafish larvae}

As outlined above, not all individual premotor interneurons of a particular type contribute equally to swimming in the tadpole. Some are more active at the start of a swimming episode when excitation is stronger and swimming frequency is higher, suggesting that some are specialized for faster swimming. Patterns of specialization within neuron types have been elegantly explored in larval zebrafish (mainly $\sim 4$ - to 5-days post-fertilization). Ritter et al. (2001) used calcium imaging to demonstrate that two groups of excitatory neurons with descending axons, circumferential ipsilateral descending interneurons (CiDs), with ipsilateral axons, and multipolar commissural descending interneurons (MCoDs), with contralateral axons, were specialized for escape and swimming responses, respectively. Later research, however, showed that the situation is more complicated. At progressively higher swimming frequencies, spinal motoneurons are recruited according to a classic size principle and in a ventral to dorsal sequence (McLean et al., 2007, 2008). Both the CiD and MCoD excitatory interneurons can also be active during swimming, but with quite different patterns of recruitment (Figure 6). The more ventral MCoDs fire only during slow swimming and are actively inhibited during faster swimming, when CiDs instead are active. Within the CiD population, the more ventral individuals fire at lower swimming speeds while progressively more dorsal individuals fire during progressively faster swimming. This pattern of recruitment differs from that in the motoneurons, because during faster swimming, the more dorsal CiDs are not simply added to the active population but instead replace the more ventral CiDs, which stop firing and show some evidence that they are inhibited. Individual CiDs are therefore not recruited according to a simple size principle but are specialized for a particular band of swimming frequencies.

An opposite pattern of recruitment within neuron types occurs for inhibitory interneurons during swimming (McLean et al., 2007). Among the reciprocal inhibitory CoBLs, the more dorsal individuals fire during the slowest swimming and the more ventral individuals are recruited during faster swimming. The same pattern of dorsoventral recruitment also occurs in circumferential ipsilateral ascending interneurons (CiAs). This second type of inhibitory interneuron has an ipsilateral ascending axon and is homologous to the hatchling tadpole aIN (Bernhardt et al., 1990; Higashijima et al., 2004b). On the basis of this homology, it might be predicted that, like tadpole aINs, zebrafish CiAs would be strongly activated during struggling. If so, then like tadpole aINs they would combine a broad multifunctionality between motor patterns with specialization according to speed during swimming.

\section{TURTLE PREMOTOR INTERNEURONS}

Not surprisingly, given a far greater complexity, definition of neuronal types in the adult turtle spinal cord is currently less advanced than in the tadpole or zebrafish larva. However, significant progress has been made in recent years allowing us to start to make inferences about probable roles of interneuron types in different behavioral responses.

\section{Turtle scratching}

Most scratch-activated spinal interneurons are rhythmically activated or rhythmically modulated and phase-locked to the scratch motor pattern (Berkowitz and Stein, 1994b; Berkowitz, 2001b,

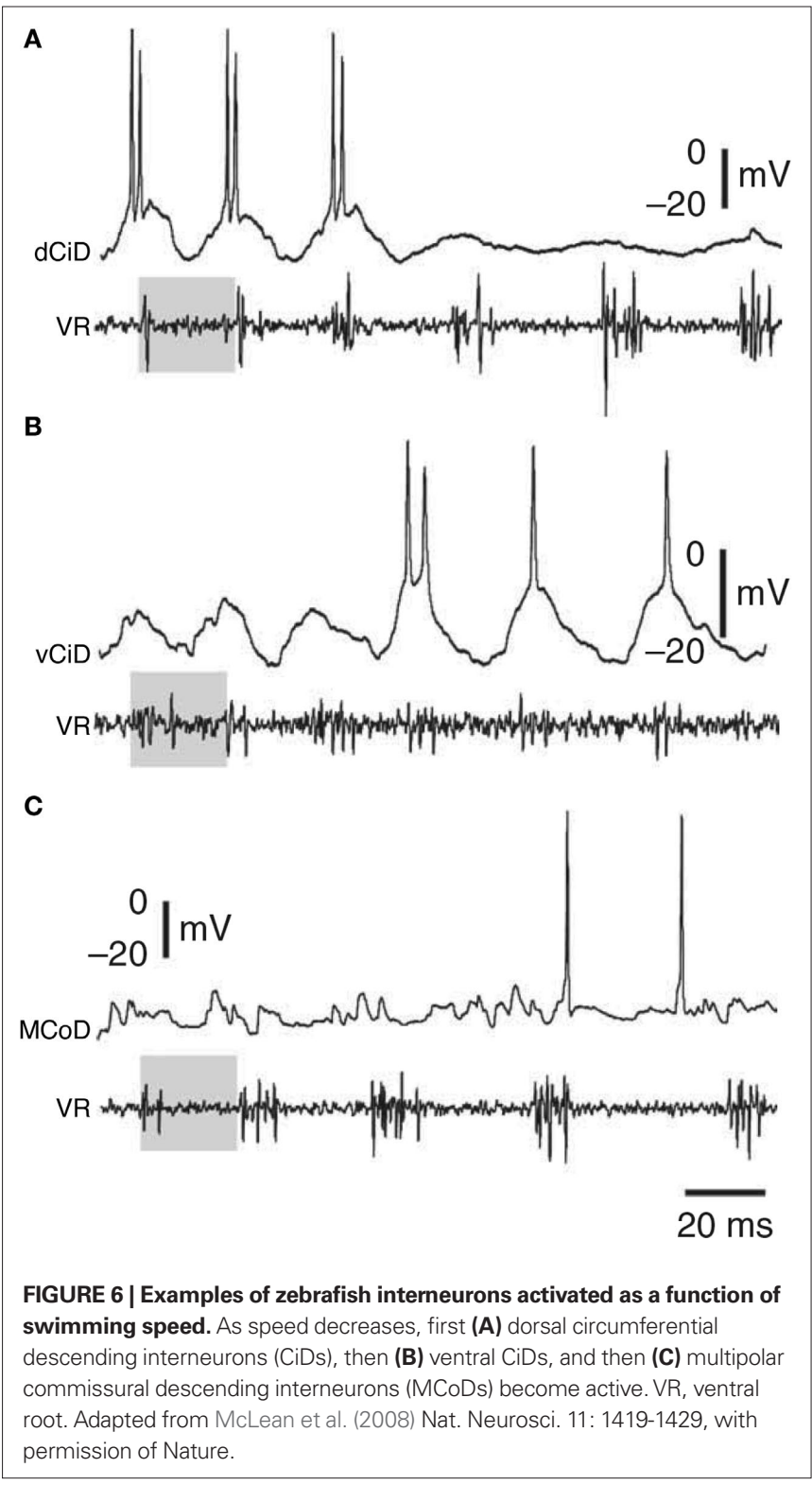

2008; Berkowitz et al., 2006). In general, broadly tuned interneurons that are activated during all three forms of scratching are also rhythmically activated or modulated (Berkowitz and Stein, 1994b; Berkowitz, 2001b). Thus, it is possible that the interneurons that select a form of scratching also contribute to rhythm and/or pattern generation. Many such interneurons have axon terminal arborizations in the ventral horn in the hindlimb enlargement of the spinal cord, consistent with their affecting hindlimb motor output relatively directly (Berkowitz, 2005). If some of these interneurons indeed contribute to rhythm and/or pattern generation, then they do so for all three forms of scratching, and in this sense are multifunctional pattern-generating neurons.

Most rhythmic scratch-activated interneurons have a consistent preferred phase of firing within the hip flexor/hip extensor activity cycle that is maintained for all three forms of scratching, despite the different knee-hip synergy in each form of scratching (Berkowitz and Stein, 1994b; Berkowitz, 2001b). It is possible 
that the correct knee-hip synergy is generated for each form of scratching without interneurons that are dedicated to knee muscle control. This might occur via differential activation, through broad tuning, of interneurons that specify different knee-hip synergies via dual outputs to knee and hip motoneurons (Berkowitz and Stein, 1994b; Berkowitz, 2001b). It is also possible that a smaller number of knee-dedicated interneurons play a key role in generating the knee motoneuron bursts (Stein and DanielsMcQueen, 2003).

Most interneurons that are rhythmically activated during scratching are also rhythmically activated during forward swimming (Berkowitz, 2002, 2008). At least some of these interneurons have axon terminal arborizations in the ventral horn of the hindlimb enlargement, consistent with their having relatively direct effects on hindlimb motor output (Berkowitz, 2008). These multifunctional "scratch/swim" interneurons potentially contribute to rhythm and/or pattern generation for both scratching and forward swimming. Some interneurons that are rhythmically activated or modulated during scratching are tonically activated during forward swimming (Berkowitz, 2002). These interneurons could potentially contribute to rhythm and/or pattern generation during scratching and provide tonic excitatory drive during swimming.

Within the set of scratch/swim interneurons is a morphologically defined group called transverse interneurons, or T neurons (Berkowitz et al., 2006). T neurons have dendrites that are elongated within the transverse plane but relatively short along the rostrocaudal axis. T neurons are strongly and rhythmically activated during all forms of scratching and are also activated during forward swimming (Figure 7), and usually during ipsilateral limb withdrawal as well (Berkowitz et al., 2006; Berkowitz, 2008). $\mathrm{T}$ neurons are good candidates to contribute to rhythm/pattern generation and/or to be last-order premotor interneurons, because
T neurons as a group have larger scratch membrane potential oscillations and reach higher peak firing rates during scratching than other scratch-activated interneurons. T neurons as a group also have briefer action potentials and afterhyperpolarizations than other scratch-activated interneurons. T neurons can also have axons that terminate within the ventral horn of the hindlimb enlargement, consistent with their having relatively direct effects on hindlimb motor output.

In addition to these multifunctional interneurons, there are other interneurons that are clearly specialized. However, while it is quite possible that some of these are premotor as in the tadpole and zebrafish, there is not yet sufficient evidence to support this and they are considered later (see Turtle swimming and limb withdrawal).

\section{INITIATION AND SELECTION OF RESPONSES: SENSORY PATHWAY INTERNEURONS}

In each species, distinct types of spinal motor patterns can be elicited by activity in distinct sets of sensory neurons or, in some cases, by different patterns of activity within a single set of sensory neurons. Spinal and cranial (for example visual and auditory) pathways may both be involved in eliciting spinal motor patterns. In intact animals, stimuli to the head lead to activity in hindbrain interneurons with axons that descend to the spinal cord to trigger a spinally generated motor pattern. Sensory neurons caudal to the head may directly activate spinal sensory interneurons that can trigger a spinally generated motor pattern or may themselves excite hindbrain descending pathways. In each of these cases, sensory pathway interneurons could select and modify the operation of premotor networks in a broadly tuned way to produce a range of motor outputs, or could act in a specialized way to select specific motor outputs. In the three

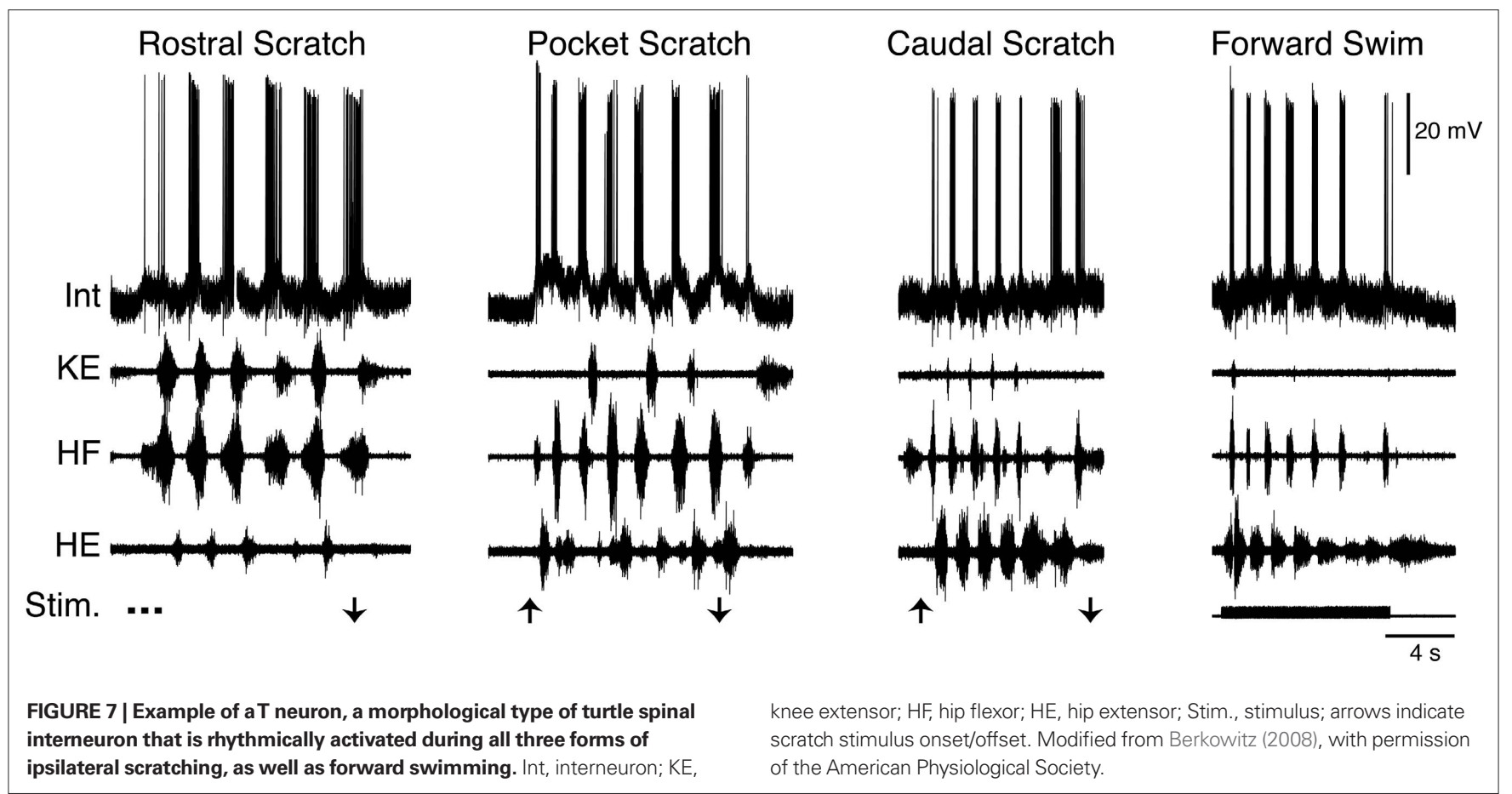


systems being described here, there are examples of both highly specialized and broadly tuned, multifunctional neurons associated with the initiation of responses.

\section{SENSORY PATHWAY INTERNEURONS IN TADPOLES}

Tadpole flexion reflexes, swimming, and struggling can all be elicited by stimulation of the trunk skin (Soffe, 1992). In the hatchling tadpole, before the appearance of dorsal root ganglia, the trunk skin is innervated by the touch-sensitive neurites of primary sensory Rohon-Beard neurons, whose cell bodies lie in columns along the dorsal part of the spinal cord (Clarke et al., 1984). Brief firing in these Rohon-Beard neurons can elicit a flexion reflex if it is very brief, but it more often elicits swimming. Sustained discharge, as when the tadpole is grasped or in response to $\sim 40-\mathrm{Hz}$ electrical stimulation, elicits struggling for the duration of the stimulus (Soffe, 1991, 1993, 1996). Selection of different motor patterns can therefore be achieved by different patterns of sensory discharge in the same sensory neurons. How can this process of motor pattern selection work? The properties of sensory pathway interneurons need to be considered.

\section{Tadpole flexion reflex and swimming}

Two types of sensory pathway interneurons relay information about brief touch of the trunk skin from the primary sensory Rohon-Beard neurons. The dorsolateral commissural (dlc) and dorsolateral ascending (dla) interneurons have axons projecting rostrally into the hindbrain on the opposite side and the same side, respectively (Roberts and Clarke, 1982; Roberts and Sillar, 1990; Li et al., 2001, 2003, 2004b). The contralateral axons of dlcs also often branch to descend. These dlc and dla sensory pathway interneurons share several features: their characteristic dorsolateral position in the cord, their adapting firing properties, their very strong, fast, glutamatergic excitation by Rohon-Beard neu- rons, and their weaker, glutamatergic excitation of motoneurons and premotor interneurons, which relies on summation of input from several pre-synaptic neurons to be effective (Li et al., 2003, 2004b). Following a brief stimulus to the trunk skin, dlcs and dlas can each quickly fire a single spike (Figure 8A). The result of the stimulus is usually a reflex motor response (flexion reflex) on the opposite side. The mechanism favoring a contralateral rather than ipsilateral response has been investigated, but remains unclear (Zhao et al., 1998). In addition to their role in flexion reflexes, dlcs and dlas are involved in the initiation of swimming (ultimately producing self-sustaining firing in members of the excitatory dIN population in the caudal hindbrain and rostral spinal cord (Soffe, 1993; Li et al., 2004a, 2006)). Both are inactive during swimming itself since they are subject to rhythmic inhibition from aINs. During struggling, strong recruitment of aIN firing and the consequent summation of this aIN inhibition prevents dlcs and dlas from firing (Soffe, 1993). The dlc and dla sensory pathway interneurons are therefore specialized for mediating flexion reflex responses and the initiation of swimming in response to brief touch.

\section{Tadpole struggling}

Historically, the gating out of dlc and dla sensory interneurons left a problem for understanding the way sustained firing in Rohon-Beard neurons evoked by $\sim 40-\mathrm{Hz}$ stimulation of the trunk skin could evoke struggling (Soffe, 1993). Evidence suggests that summation of weak Rohon-Beard excitation provides excitation to premotor interneurons on the same side. In addition, a further type of sensory pathway commissural interneuron has now been described (Li et al., 2007). Excitatory commissural interneurons (ecINs) are excited by Rohon-Beard neurons and have axons that project rostrally and caudally on the opposite side, where they excite motoneurons and premotor

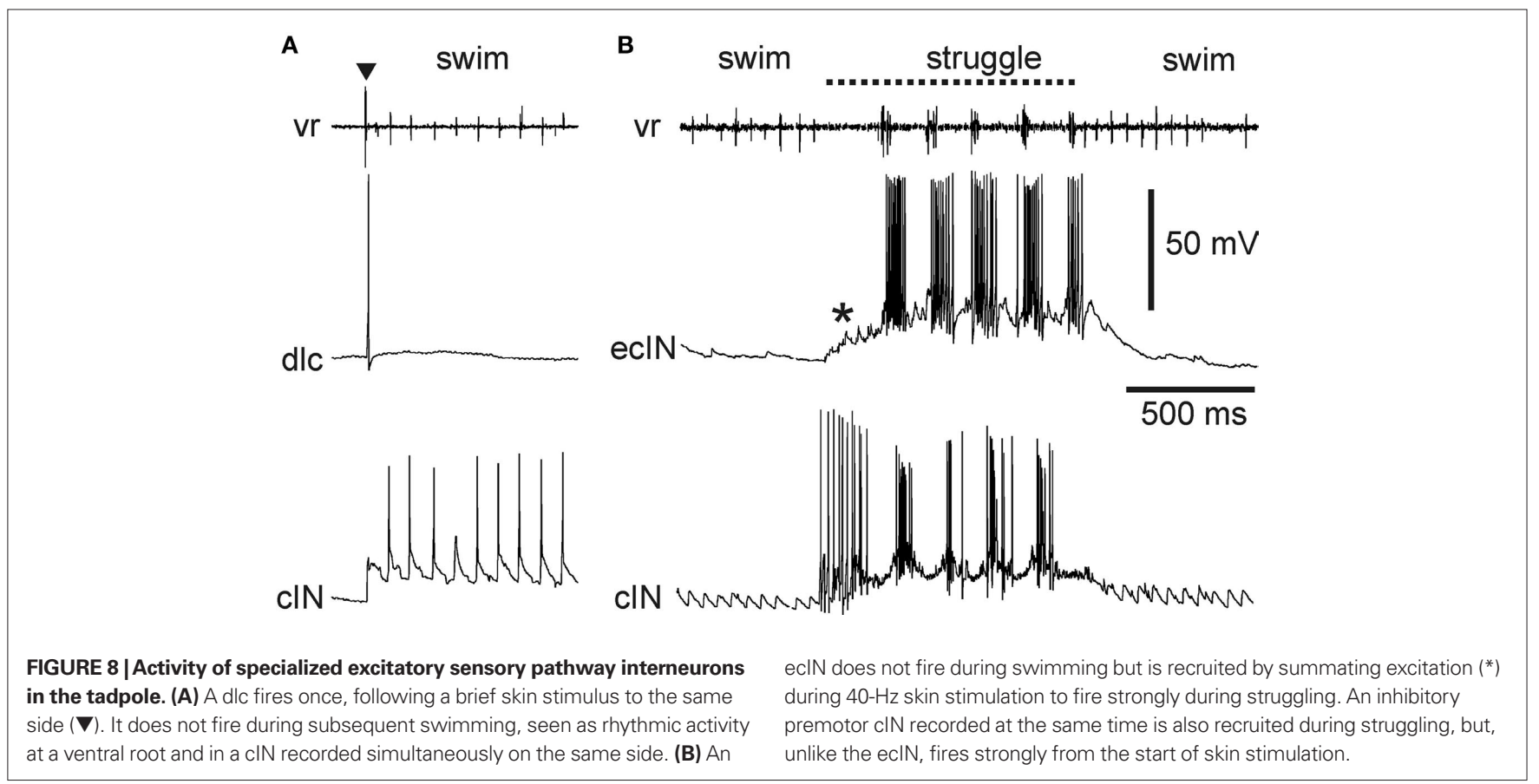


interneurons. Excitation of and by ecINs is glutamatergic and is relatively weak, so it relies on summation to be effective. The significance of this is that ecINs do not fire following a brief skin stimulus or during swimming because they are only recruited during sustained sensory discharge that produces summating excitation (Figure 8B). Sensory excitation of ecINs is reinforced during struggling by rhythmic drive from the struggling circuit (probably from dINrs, although this has not been confirmed). The ecINs are therefore an additional type of specialized sensory pathway interneuron that plays a role in the selection and maintenance of struggling.

\section{SENSORY PATHWAY NEURONS IN ZEBRAFISH LARVAE}

Although zebrafish larvae and hatchling tadpoles share a number of features, one important difference is the central role played by the Mauthner and Mauthner-like neurons in initiation of responses of the zebrafish from an early age ( $\sim 40$-h post-fertilization) (Eaton et al., 1977a). There is no evidence for Mauthner neurons eliciting short-latency responses in Xenopus tadpoles until later in larval development. Escape in zebrafish is triggered by activity of the Mauthner cells and other brainstem neurons that project to the spinal cord, including homologues of the Mauthner cells in different hindbrain segments (Kimmel et al., 1982; Metcalfe et al., 1986; Gahtan et al., 2002). Escape responses with different trajectories may be triggered by different combinations of these descending neurons (O’Malley et al., 1996; Liu and Fetcho, 1999; Gahtan et al., 2002). The initial component of escape, the C-start, occurs exceptionally fast because the Mauthner cell directly excites contralateral motoneurons and interneurons (including the specialized inhibitory CoLos; see above). In this sense, the Mauthner cells may be hindbrain analogues of the spinal dlc sensory pathway interneurons in the tadpole, which are also specialized interneurons that trigger a contralateral response.

Escape is frequently followed by swimming. Swimming can also be evoked without an initial C-flexion by stimuli to the head or tail, but less is currently known about these other sensory pathways to trigger swimming. Tail stimuli excite Rohon-Beard neurons, which then excite commissural primary ascending interneurons (CoPAs), probably the spinal homologues of tadpole dlcs (Gleason et al., 2003; Higashijima et al., 2004b). Like tadpole dlcs, CoPAs are dorsally situated, have longitudinally extensive dendrites and an axon that crosses the cord to project rostrally, and are glutamatergic (Hale et al., 2001; Higashijima et al., 2004c). CoPAs are probably specialized sensory pathway interneurons involved in initiation of non-escape swimming (Hale et al., 2001). The much less numerous dorsal longitudinal ascending interneurons (DoLAs) are also likely sensory pathway interneurons; their ipsilateral ascending axon makes them possible homologues of the tadpole dlas. If so, they too may be specialized to elicit swimming following ipsilateral tail stimulation, but this is not yet known.

Commissural secondary ascending interneurons (CoSAs) have a single axon that projects rostrally on the opposite side. CoSAs are heterogeneous and include both glycinergic and glutamatergic phenotypes (Higashijima et al., 2004a). The functions of these two phenotypes are presumably different but neither is yet known. Liao and Fetcho (2008) speculate that CoSAs are sensory interneurons (like CoPAs). Although their behavioral role is not yet clear, it is clear that glycinergic CoSAs are broadly multifunctional, as they fire during both swimming and struggling and, in some cases, escape (Liao and Fetcho, 2008).

\section{TURTLES}

In turtles, different spinally generated limb motor patterns are generally triggered by activity in different primary sensory neurons or supraspinal descending neurons. Descending axons in the contralateral lateral funiculus (thought to be reticulospinal) can trigger swimming motor patterns and movements (Lennard and Stein, 1977; Juranek and Currie, 2000). Sensory neurons that innervate different regions of the body surface trigger different forms of scratching (Mortin et al., 1985; Robertson et al., 1985; Mortin and Stein, 1990) and sensory neurons that innervate the hindlimb skin trigger limb withdrawal (Stein et al., 1982). An exception, however, is for stimulation in a transition zone between scratch forms (Mortin et al., 1985; Robertson et al., 1985; Mortin and Stein, 1990). In this case, it seems likely that activity in the same set of sensory neurons can trigger either of two forms of scratching or a blend of the two. It is possible, though unlikely, that stimulation in this region actually activates two separate sets of sensory neurons, each of which triggers only one form of scratching.

\section{Turtle scratching}

At the level of spinal interneurons, perhaps the simplest hypothesis is that there is a separate set of sensory interneurons receiving inputs from primary sensory neurons that innervate each scratch form receptive field. Thus, activity in each set of sensory neurons would cause activity in a particular set of interneurons, which would in turn trigger a particular form of scratching. This simple idea, however, has been undermined by recordings from many individual scratch-activated spinal interneurons, both extracellularly and intracellularly, each of which was activated during all three forms of scratching (Berkowitz and Stein, 1994a,b; Berkowitz, 2001a,b, 2002, 2005; Berkowitz et al., 2006). Thus, the vast majority of scratchactivated interneurons appear to be multifunctional in the sense that they are activated during multiple forms of scratching. The activity of these interneurons can nonetheless signal the body surface site stimulated, because many of these interneurons are broadly tuned to a particular region of the body surface and are progressively less activated by stimulation further away from this region (Berkowitz and Stein, 1994a; Berkowitz, 2001a). Thus, as a population, these multifunctional interneurons can in principle signal which site has been stimulated and trigger an appropriate form of scratching. Therefore, a common set of multifunctional spinal interneurons may be responsible for initiating scratching, with differential activity across this population determining which form is produced. If so, this is another case in which the distinction between multifunctional and specialized contribution by one set of interneurons is not clear-cut.

\section{Turtle swimming and limb withdrawal}

When forward swimming and limb withdrawal are brought into the picture, however, the idea that a single set of multifunctional interneurons triggers all of these behaviors is not consistent with all of the data (Berkowitz, 2002, 2007,2008). It is true that many spinal interneurons are activated during both scratching and forward swimming motor patterns (scratch/swim neurons) (Berkowitz, 2002, 2008) (Figure 7). 
Many are also activated during limb withdrawal (Berkowitz, 2005). In addition to these multifunctional interneurons, however, there are at least two functionally defined categories of behaviorally specialized interneurons. One group, scratch-specialized neurons (Figure 9), are activated during all forms of scratching but are not activated during forward swimming (Berkowitz, 2002, 2008). In at least some cases, scratch-specialized interneurons receive hyperpolarizing inhibition during forward swimming (Figures 9C,D) (Berkowitz, 2008). As a group, scratch-specialized neurons are less likely than scratch/swim neurons to be activated during ipsilateral or contralateral limb withdrawal (Berkowitz, 2002). Thus, to some extent, scratch/swim neurons are general "multipurpose" limb motor control neurons while scratch-specialized neurons are quite specialized.

Another group, flexion reflex-selective neurons (Figure 10), are excited strongly and at short-latency during foot skin stimulation that evokes limb withdrawal (Figures 10A,B), but are not activated during scratching (Figure 10C) or forward swimming (Figure 10D) (Berkowitz, 2007). In most cases tested, these flexion reflex-selective neurons receive hyperpolarizing inhibition during both scratching and swimming. This hyperpolarization can be maximal during the hip flexor phase of scratching and swimming (Figure 10E), even though these neurons are strongly activated during the hip flexor burst of limb withdrawal. Flexion reflex-selective neurons have so far been found only within the dorsal horn, in contrast to multifunctional interneurons activated during scratching and swimming, which are most often found in the intermediate zone and ventral horn.

Thus, both scratch-specialized neurons and flexion reflexselective neurons are specialized for a particular behavior or set of behaviors, rather than a particular muscle or phase, and do not contribute to other spinally generated behaviors that involve the same motoneurons and muscles.

\section{COMMON FEATURES REVEALED BY TADPOLE, ZEBRAFISH AND TURTLE}

Clearly the most striking common feature, as stated at the outset, is that selection and expression of different motor responses in hatchling tadpoles, larval zebrafish, and adult turtles operating through the same neuromuscular machinery involves a combination of multifunctional and specialized neurons. Can we say more? In the vertebrate nervous system, unlike the situation commonly found among invertebrates, activity involves populations of similar neuron types
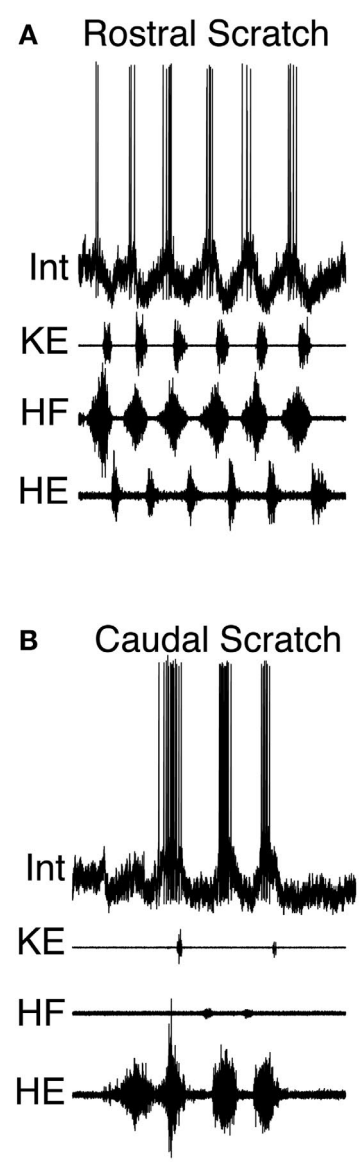

FIGURE 9 | Example of a turtle scratch-specialized interneuron during fictive motor patterns. Activity of the interneuron (Int) during (A) rostral scratching, (B) caudal scratching, and (C,D) forward swimming. Note that the interneuron is hyperpolarized for several
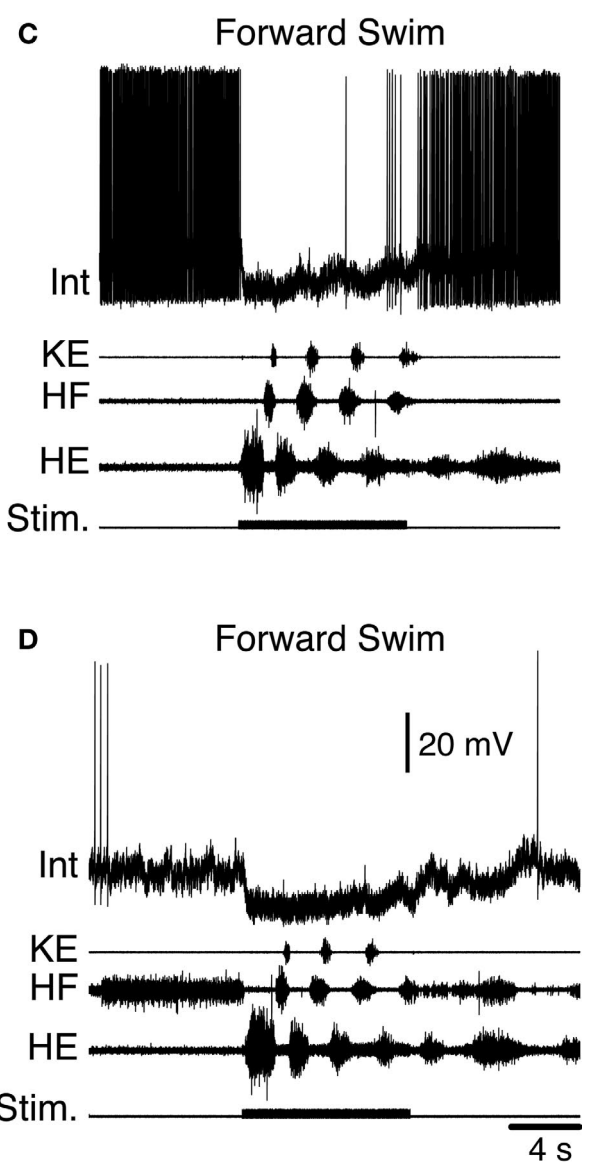

seconds beyond the swim-evoking stimulus, as the motor pattern continues. $\mathrm{KE}$, knee extensor; HF, hip flexor; HE, hip extensor; Stim., stimulus. Modified from Berkowitz (2008), with permission of the American Physiological Society. 


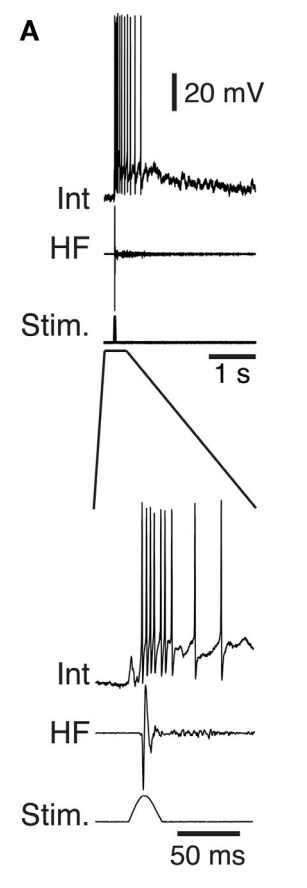

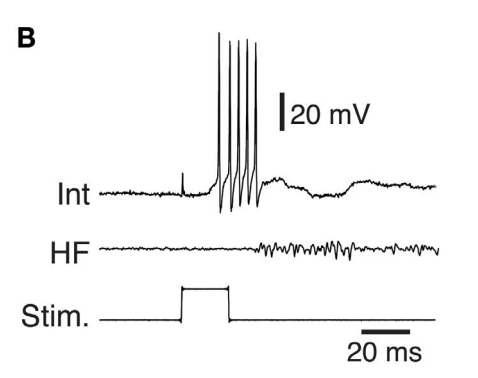

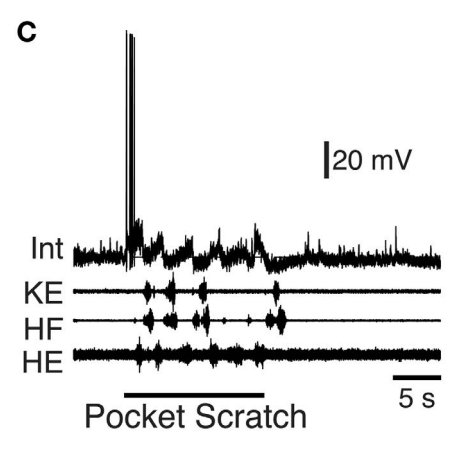

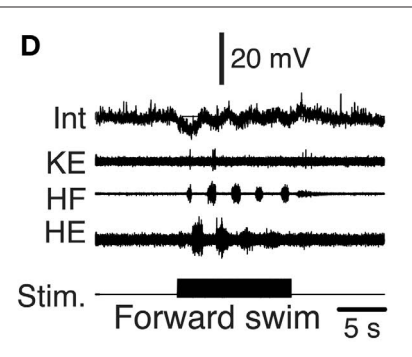

E

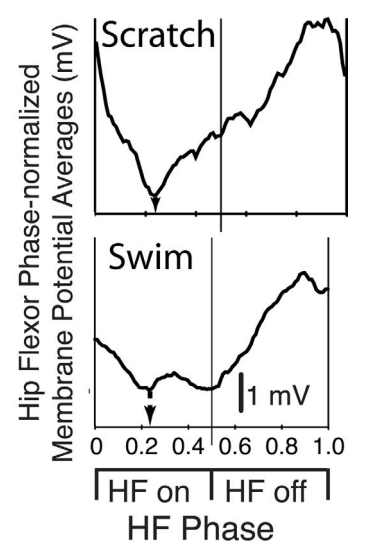

FIGURE 10 | Example of a flexion reflex-selective interneuron during turtle fictive motor patterns. Activity of the interneuron (Int) during (A) a tap to the foot that evokes withdrawal (lower record expands the early part of the response shown above), (B) an electrical stimulus to the foot skin, (C) pocket scratching, and (D) forward swimming. Note that the cell is active at the start of scratch stimulation, but not during the scratch motor pattern; it is rhythmically hyperpolarized during both scratching and swimming. (E) Phase-averaged membrane potential of this neuron during scratching and swimming. HF, hip flexor; Stim., stimulus; KE, knee extensor; HE, hip extensor. Modified from Berkowitz (2007), with permission of the Society for Neuroscience. rather than individual, identifiable neurons. We have therefore asked whether particular types or classes of vertebrate neurons, rather than simply individuals, are primarily multifunctional or specialized. In the tadpole, where spinal neuron types can already be distinguished with some confidence, it has been possible to designate some types, such as the inhibitory premotor interneurons, as multifunctional and others, such as the main sensory pathway interneurons, as specialized. A similar picture is emerging in the zebrafish larva: the main reciprocal inhibitory interneurons are multifunctional while others, such as the Mauthner neurons and the associated inhibitory interneurons that drive and coordinate the escape response are highly specialized. Characterization of neuron types in the far more complex adult turtle spinal cord is at an earlier stage, but here, too, the involvement of particular neuron types can be designated in a similar way. The clearest example is the morphologically defined $\mathrm{T}$ interneurons, which are a consistently multifunctional neuron type.

However, members of neuronal populations are not identical, and although different neuron types or classes may be designated as typically multifunctional or specialized, individuals within the population vary. This is seen among tadpole premotor interneurons: while inhibitory cINs are typically multifunctional, some individuals that fire during struggling may hardly fire during swimming, or only during faster swimming, when excitation is stronger. These differences have been most clearly highlighted in the very organized patterns of recruitment seen in zebrafish larvae during swimming at different frequencies. In the turtle, too, individuals from the broadly multifunctional population of scratch/swim neurons do not fire equally in all situations and therefore show a degree of specialization. For example, while all T neurons studied were activated during ipsilateral scratching and forward swimming, most, but not all, were activated during ipsilateral limb withdrawal and contralateral scratching, while only a small fraction was active during contralateral limb withdrawal. Clearly, there can be subtle patterns of specialization even within broadly multifunctional groups.

Is it possible to identify any common principles relating to the kinds of neurons that are multifunctional or specialized? We might expect to find multifunctional neurons where different responses have certain shared features. For example, in animals which move using trunk muscles, left and right sides are always antagonists and could share multifunctional reciprocal inhibitory interneurons. This certainly appears to be the case for the reciprocal inhibitory interneurons in the tadpole (cINs) and zebrafish larva (CoBLs), which are active during swimming and struggling. In the turtle, it is possible that T neurons or other highly rhythmic and multifunctional interneurons also mediate reciprocal inhibition between functional antagonists, such as hip flexors and extensors, which alternate during all forms of scratching and swimming. T neurons can have axon terminal arborizations in the ventral horn, so although their neurotransmitters are not known, they are good candidates to be CPG components and/or premotor interneurons. For limbed animals, the situation is more complex than for animals that only make axial movements; muscles can be antagonists for one action 
but synergists for another, so we might expect that some CPG neurons are not multifunctional. Overall, though, more information is needed for us to be able to reveal whether there are any common patterns in the distribution of multifunctionality and specialization among interneuron types across different classes of vertebrates.

\section{FUTURE STUDIES}

Future work must better determine the differential effects of behaviorally specialized and multifunctional spinal interneurons in all three species. There is much more to be learned about how specific types of zebrafish interneurons, especially excitatory spinal interneurons, are activated during struggling. In the tadpole, details still need to be resolved about exactly how swimming and struggling are initiated following different sensory stimuli. It is also not known how the status and function of interneuron types in the hatchling tadpole change as it develops to larval stages like those studied in the zebrafish and as its behavior becomes more diverse, such as with the appearance of Mauthner cell-initiated escape responses. Identification of turtle spinal interneuron types greatly lags that of tadpole and zebrafish, largely due to the greater size and complexity of the spinal cord in an adult, limbed vertebrate, as well as technical limitations. A focus of the turtle work will be to discover the neurotransmitters and synaptic targets of specialized and multifunctional interneurons.

Types of spinal interneurons found in one species may predict the existence of analogous or homologous types of spinal interneurons in another species. For example, both zebrafish CiAs and tadpole aINs express the transcription factor Engrailed-1, are glycinergic, have an ipsilateral ascending axon, and are rhythmically active during swimming (Higashijima et al., 2004b; Li et al., 2004a). We would expect further homologies, so it is likely that zebrafish struggling can be triggered by repetitive spikes in trunk skin sensory neurons and involves struggling-specialized excitatory interneurons that deliver prolonged excitation to motoneurons and other interneurons, like dINrs and ecINs do in tadpoles. It is also likely that tadpole escape-specialized spinal interneurons will be found that mediate fast Mauthner excitation of contralateral spinal motoneurons. There may also be tadpole and turtle interneurons specialized for slow swimming, as in zebrafish. It will be of interest to see if Kolmer-Agduhr cells in tadpoles provide excitatory drive to the swimming network as they have been proposed to do in zebrafish (Wyart et al., 2009).

\section{BROADER COMPARISONS}

Does a combination of multifunctional and specialized interneurons mediate behavioral selection and generation in other species as well? Studies of mollusks have highlighted the role played

\section{REFERENCES}

Baekey, D. M., Morris, K. F., Gestreau, C., Li, Z., Lindsey, B. G., and Shannon, R. (2001). Medullary respiratory neurones and control of laryngeal motoneurones during fictive eupnoea and cough in the cat.J. Physiol. (Lond.) 534, 565-581.

Bekoff, A., Nusbaum, M. P., Sabichi, A. L., and Clifford, M. (1987). Neural control of limb coordination. I. Comparison of hatching and walking motor output patterns in normal and deafferented chicks. J. Neurosci. 7, 2320-2330.

Berkinblit,M.B., Deliagina, T.G., Feldman, A. G., Gelfand, I. M., and Orlovsky, G. N. (1978). Generation of scratching. II. Nonregular regimes of generation. J. Neurophysiol. 41, 1058-1069. by mutual inhibition between circuits for competing behaviors (Kovac and Davis, 1977, 1980; Jing and Gillette, 1995), as previously suggested by Tinbergen (1951), a role that requires specialized neurons. But the interactions between these circuits have been shown to be more complex than simple mutual inhibition; they involve reconfiguration and changing coalitions of largely multifunctional neurons (Kristan and Gillette, 2007). It is also now clear that both ingestive and egestive behaviors in Aplysia (Jing and Weiss, 2001; Jing et al., 2004) and swimming and crawling in leeches (Briggman and Kristan, 2006, 2008) are produced by combinations of multifunctional and specialized interneurons. In lampreys, most reticulospinal neurons active during swimming movements are also active during crawling, while some are only active during swimming (Zelenin, 2005). In rodents, different forms of breathing and swallowing motor patterns clearly involve many multifunctional brainstem interneurons (Grelot et al., 1993; Oku et al., 1994; Gestreau et al., 1996, 2000, 2005; Lieske et al., 2000; Baekey et al., 2001; Shiba et al., 2007), but also some specialized interneurons (Shiba et al., 2007). In cats, Renshaw cells and Ia inhibitory interneurons as groups are each activated during both locomotor and scratching motor patterns (Feldman and Orlovsky, 1975; Deliagina and Orlovsky, 1980; Deliagina and Feldman, 1981; Pratt and Jordan, 1987). Also, individual interneurons are activated during both scratching motor patterns and spontaneous slow oscillations that were probably locomotor (Berkinblit et al., 1978). Recent evidence makes it likely that there are also specialized interneurons for cat locomotion or scratching (Frigon and Gossard, 2010), but they have not yet been described.

Clearly, the combined action of multifunctional and specialized neurons in behavioral selection and generation is not restricted to the three vertebrate systems we have reviewed here. A future goal of comparative studies must be the search for common principles in the deployment of multifunctional or specialized neurons. Comparisons between the three species we have focused on and others, including mammals, have the potential to reveal common vertebrate mechanisms of motor pattern selection and generation. The organization of multifunctional and specialized spinal cord and hindbrain networks to produce appropriate behavior in each circumstance may also have implications for how higher-order brain circuits are organized to select among a wider array of more complex behaviors.

\section{ACKNOWLEDGMENTS}

Work on turtles was supported by National Science Foundation award IBN-0349620 to A.B., while work on tadpoles was supported by Wellcome Trust grants to Alan Roberts and Stephen R. Soffe.
Berkowitz, A. (2001a). Broadly tuned spinal neurons for each form of fictive scratching in spinal turtles. $J$. Neurophysiol. 86, 1017-1025.

Berkowitz, A. (2001b). Rhythmicity of spinal neurons activated during each form of fictive scratching in spinal turtles. J. Neurophysiol. 86, 1026-1036.

Berkowitz, A. (2002). Both shared and specialized spinal circuitry for scratching and swimming in turtles. J. Comp. Physiol. A 188, 225-234.

Berkowitz,A. (2005). Physiology and morphology indicate that individual spinal interneurons contribute to diverse limb movements. J. Neurophysiol. 94, 4455-4470.

Berkowitz,A.(2007).Spinalinterneurons that are selectively activated during fictive flexion reflex. J. Neurosci. 27, 4634-4641. 
Berkowitz, A. (2008). Physiology and morphology of shared and specialized spinal interneurons for locomotion and scratching. J. Neurophysiol. 99, 2887-2901.

Berkowitz,A., and Stein,P.S.(1994a).Activity of descending propriospinal axons in the turtle hindlimb enlargement during two forms of fictive scratching: broad tuning to regions of the body surface. $J$. Neurosci. 14, 5089-5104.

Berkowitz, A., and Stein, P. S. (1994b). Activity of descending propriospinal axons in the turtle hindlimb enlargement during two forms of fictive scratching: phase analyses. J. Neurosci. 14, 5105-5119.

Berkowitz, A., Yosten, G. L., and Ballard, R. M. (2006). Somato-dendritic morphology predicts physiology for neurons that contribute to several kinds of limb movements. J. Neurophysiol. 95, 2821-2831.

Bernhardt, R. R., Chitnis, A. B., Lindamer, L., and Kuwada, J. Y. (1990). Identification of spinal neurons in the embryonic and larval zebrafish. J. Comp. Neurol. 302, 603-616.

Bhatt, D. H., McLean, D. L., Hale, M. E., and Fetcho, J. R. (2007). Grading movement strength by changes in firing intensity versus recruitment of spinal interneurons. Neuron 53, 91-102.

Bickel, A. (1897). Recherches sur les fonctions de la moelle epiniere chez les tortues. Rev. Med. Suisse Romande 295-302.

Boothby, K. M., and Roberts, A. (1995). Effects of site and strength of tactile stimulation on the swimming responses of Xenopus laevis tadpoles. J. Zool. 235, 113-125.

Briggman, K. L. and Kristan, W. B. Jr. (2006). Imaging dedicated and multifunctional neural circuits generating distinct behaviors. J. Neurosci. 26, 10925-10933.

Briggman, K. L., and Kristan, W. B. (2008). Multifunctional pattern-generating circuits. Annu. Rev. Neurosci. 31, 271-294.

Budick, S. A., and O'Malley, D. M. (2000). Locomotor repertoire of the larval zebrafish: swimming, turning and prey capture. J. Exp. Biol. 203, 2565-2579.

Buss, R. R., and Drapeau, P. (2001). Synaptic drive to motoneurons during fictive swimming in the developing zebrafish. J. Neurophysiol. 86, 197-210.

Buss, R. R., and Drapeau, P. (2002). Activation of embryonic red and white muscle fibers during fictive swimming in the developing zebrafish. J. Neurophysiol. 87, 1244-1251.

Carter, M. C., and Smith, J. L. (1986). Simultaneous control of two rhythmical behaviors. II. Hindlimb walking with the paw-shake response in spinal cat. J. Neurophysiol. 56, 184-195.

Clarke, J. D. W., Hayes, B. P., Hunt, S. P., and Roberts, A. (1984). Sensory physiology, anatomy and immunohistochemistry of Rohon-Beard neurones in embryos of Xenopus laevis. J. Physiol. 348, 511-525.

Currie, S. N., and Stein, P. S. (1989). Interruptions of fictive scratch motor rhythms by activation of cutaneous flexion reflex afferents in the turtle. $J$. Neurosci. 9, 488-496.

Dale, N., and Roberts, A. (1985). Dualcomponent amino-acid-mediated synaptic potentials: excitatory drive for swimming in Xenopus embryos. J. Physiol. 363, 35-59.

Deliagina, T. G., and Feldman, A. G. (1981). Activity of Renshaw cells during fictive scratch reflex in cat. Exp. Brain Res. 42, 108-115.

Deliagina, T.G., and Orlovsky,G.N.(1980). Activity of Ia inhibitory interneurons during fictitious scratch reflex in the cat. Brain Res. 193, 439-447.

Drapeau, P., Saint-Amant, L., Buss, R. R., Chong, M., McDearmid, J. R., and Brustein, E. (2002). Development of the locomotor network in zebrafish. Prog. Neurobiol. 68, 85-111.

Earhart, G. M., and Stein, P. S. (2000a). Scratch-swim hybrids in the spinal turtle: blending of rostral scratch and forward swim. J. Neurophysiol. 83, 156-165.

Earhart, G. M., and Stein, P. S. (2000b). Step, swim, and scratch motor patterns in the turtle. J. Neurophysiol. 84, 2181-2190.

Eaton, R. C., Bombardieri, R. A., and Meyer, D. L. (1977a). The Mauthnerinitiated startle response in teleost fish. J. Exp. Biol. 66, 65-81.

Eaton, R. C., Farley, R. D., Kimmel, C. B., and Schabtach, E. (1977b). Functional development in the Mauthner cell system of embryos and larvae of the zebra fish. J. Neurobiol. 8, 151-172.

Feldman, A. G., and Orlovsky, G. N. (1975). Activity of interneurons mediating reciprocal Ia inhibition during locomotion. Brain Res. 84, 181-194.

Fetcho, J. R. (1990). Morphological variability, segmental relationships, and functional role of a class of commissural interneurons in the spinal cord of goldfish. J. Comp. Neurol. 299 283-298.

Fetcho, J. R., Higashijima, S., and McLean, D. L. (2008). Zebrafish and motor control over the last decade. Brain Res. Rev. 57, 86-93.

Fetcho, J. R., and O'Malley, D. M. (1995). Visualization of active neural circuitry in the spinal cord of intact zebrafish. J. Neurophysiol. 73, 399-406.

Field, E. C., and Stein, P. S. (1997). Spinal cord coordination of hindlimb move- ments in the turtle: intralimb temporal relationships during scratching and swimming. J. Neurophysiol. 78, 1394-1403.

Frigon, A., and Gossard, J. P. (2010). Evidence for specialized rhythmgenerating mechanisms in the adult mammalian spinal cord. J. Neurosci. 30, 7061-7071.

Gahtan, E., Sankrithi, N., Campos, J. B., and O'Malley, D. M. (2002). Evidence for a widespread brain stem escape network in larval zebrafish. J. Neurophysiol. 87, 608-614.

Gelfand, I. M., Orlovsky, G. N., and Shik, M. L. (1988). "Locomotion and scratching in tetrapods," in Neural Control of Rhythmic Movements in Vertebrates, A. H. Cohen, S. Rossignol, and S. Grillner (New York: John Wiley \& Sons), 167-199.

Gestreau, C., Dutschmann, M., Obled, S. and Bianchi,A.L. (2005). Activation of XII motoneurons and premotor neurons during various oropharyngeal behaviors. Respir. Physiol. Neurobiol. 147, 159-176.

Gestreau, C., Grelot, L., and Bianchi, A. L. (2000). Activity of respiratory laryngeal motoneurons during fictive coughing and swallowing. Exp. Brain Res. 130, 27-34.

Gestreau, C., Milano, S., Bianchi, A. L. and Grelot, L. (1996). Activity of dorsal respiratory group inspiratory neurons during laryngeal-induced fictive coughing and swallowing in decerebrate cats. Exp. Brain Res. 108, 247-256.

Gleason, M. R., Higashijima, S., Dallman, J., Liu, K., Mandel, G., and Fetcho, J.R. (2003). Translocation of CaM kinase II to synaptic sites in vivo. Nat. Neurosci. 6, 217-218.

Goulding, M. (2009). Circuits controlling vertebrate locomotion: moving in a new direction. Nat. Rev. Neurosci. 10 507-518.

Goulding, M., Lanuza, G., Sapir, T., and Narayan, S. (2002). The formation of sensorimotor circuits. Curr. Opin. Neurobiol. 12, 508-515.

Green, C. S., and Soffe, S. R. (1996) Transitions between two different motor patterns in Xenopus embryos. J. Comp. Physiol. A. 178, 279-291.

Grelot,L., Milano, S., Portillo, F, and Miller, A. D. (1993). Respiratory interneurons of the lower cervical (C4-C5) cord: membrane potential changes during fictive coughing, vomiting, and swallowing in the decerebrate cat. Pflugers Arch. 425, 313-320.

Grillner, S. (1981). "Control of locomotion in bipeds, tetrapods, and fish," in Handbook of Physiology, Sect. 1, The Nervous System, Vol. 2, Motor Control, ed. V. Brooks (American Physiological Society, Bethesda, MD) 1179-1236.
Grillner, S. (1985). Neurobiological bases of rhythmic motor acts in vertebrates. Science 228, 143-149.

Hale, M. E., Ritter, D. A., and Fetcho, J. R. (2001). A confocal study of spinal interneurons in living larval zebrafish. J. Comp. Neurol. 437, 1-16.

Hall, M. (1833). On the reflex function of the medulla oblongata and medulla spinalis. Phil. Trans. R. Soc. Lond. 123, 635-665.

Harris-Warrick, R. M., Marder, E., Selverston, A. I., and Moulins, M. (1992). Dynamic Biological Networks: The Stomatogastric Nervous System. Cambridge, MA: The MIT Press.

Higashijima, S., Mandel, G., and Fetcho, J. R. (2004a). Distribution of prospective glutamatergic, glycinergic, and GABAergic neurons in embryonic and larval zebrafish. J. Comp. Neurol. 480, 1-18.

Higashijima, S., Masino, M.A., Mandel, G., and Fetcho, J. R. (2004b). Engrailed-1 expression marks a primitive class of inhibitory spinal interneuron. $J$. Neurosci. 24, 5827-5839.

Higashijima, S., Schaefer, M., and Fetcho, J. R. (2004c). Neurotransmitter properties of spinal interneurons in embryonic and larval zebrafish. J. Comp. Neurol. 480, 19-37.

Jankowska, E., Jukes, M. G. M., Lund, S. and Lundberg, A. (1967). The effect of DOPA on the spinal cord. 5. Reciprocal organization of pathways transmitting excitatory action to alpha motoneurones of flexors and extensors. Acta Physiol. Scand. 70, 369-388.

Jessell, T. M. (2000). Neuronal specification in the spinal cord: inductive signals and transcriptional codes. Nat. Rev. Genet. 1, 20-29.

Jing, J., Cropper, E. C., Hurwitz, I., and Weiss, K. R. (2004). The construction of movement with behavior-specific and behavior-independent modules. J. Neurosci. 24, 6315-6325.

Jing, J., and Gillette, R. (1995). Neuronal elements that mediate escape swimming and suppress feeding behavior in the predatory sea slug Pleurobranchaea. J. Neurophysiol. 74, 1900-1910.

Jing, J., and Weiss, K. R. (2001). Neural mechanisms of motor program switching in Aplysia. J. Neurosci. 21, 7349-7362.

Johnston, R. M., and Bekoff, A. (1996). Patterns of muscle activity during different behaviors in chicks: implications for neural control. J. Comp. Physiol. A. 179, 169-184.

Juranek, J., and Currie, S. N. (2000). Electrically evoked fictive swimming in the low-spinal immobilized turtle. J. Neurophysiol. 83, 146-155.

Kahn, J. A., and Roberts, A. (1982). The neuromuscular basis of rhythmic 
struggling movements in embryos of Xenopus laevis. J. Exp. Biol. 99, 197-205.

Kahn, J. A., Roberts, A., and Kashin, S. M. (1982). The neuromuscular basis of swimming movements in embryos of the amphibian Xenopus laevis. J. Exp. Biol. 99, 175-184.

Katz, P. S., and Hooper, S. L. (2007). Invertebrate central pattern generators. in Invertebrate Neurobiology, eds G. North and R. J. Greenspan (Cold Spring Harbor, NY: Cold Spring Harbor Laboratory Press), 251-279.

Kimmel, C. B., Powell, S. L., and Metcalfe, W. K. (1982). Brain neurons which project to the spinal cord in young larvae of the zebrafish.J. Comp. Neurol. 205, 112-127.

Kimura, Y., Okamura, Y., and Higashijima, S. (2006). alx, a zebrafish homolog of Chx10, marks ipsilateral descending excitatory interneurons that participate in the regulation of spinal locomotor circuits. J. Neurosci. 26, 5684-5697.

Kovac, M. P., and Davis, W. J. (1977). Behavioral choice: neural mechanisms in Pleurobranchaea. Science 198, 632-634.

Kovac, M. P., and Davis, W. J. (1980). Neural mechanism underlying behavioral choice in Pleurobranchaea. $J$. Neurophysiol. 43, 469-487.

Kristan, W., and Gillette, R. (2007). "Behavioral choice," in Invertebrate Neurobiology, eds G. North and R. J. Greenspan (Cold Spring Harbor, NY: Cold Spring Harbor Laboratory Press), 533-553.

Kupfermann, I., and Weiss, K. R. (2001). Motor program selection in simple model systems. Curr. Opin. Neurobiol. 11, 673-677.

Lennard, P. R., and Stein, P. S. (1977). Swimming movements elicited by electrical stimulation of turtle spinal cord. I. Low-spinal and intact preparations. J. Neurophysiol. 40, 768-778.

Li, W. C., Higashijima, S., Parry, D. M., Roberts, A., and Soffe, S. R. (2004a). Primitive roles for inhibitory interneurons in developing frog spinal cord. $J$. Neurosci. 24, 5840-5848.

Li, W. C., Soffe, S. R., and Roberts, A. (2004b). Dorsal spinal interneurons forming a primitive, cutaneous sensory pathway. J. Neurophysiol. 92, 895-904.

Li, W. C., Soffe, S. R., and Roberts, A. (2004c). Glutamate and acetylcholine corelease at developing synapses. Proc. Natl. Acad. Sci. U.S.A. 101, 15488-15493.

Li, W. C., Perrins, R., Soffe, S. R., Yoshida, M., Walford,A., and Roberts, A. (2001). Defining classes of spinal interneuron and their axonal projections in hatch- ling Xenopus laevis tadpoles. J. Comp. Neurol. 441, 248-265.

Li, W. C., Roberts, A., and Soffe, S. R. (2009). Locomotor rhythm maintenance: electrical coupling among premotor excitatory interneurons in the brainstem and spinal cord of young Xenopus tadpoles. J. Physiol. 587, 1677-1693.

Li, W.-C., Sautois, B., Roberts, A., and Soffe, S. R. (2007). Reconfiguration of a vertebrate motor network: specific neuron recruitment and context-dependent synaptic plasticity. J. Neurosci. 27, 12267-12276.

Li, W. C., Soffe, S. R., and Roberts, A. (2002). Spinal inhibitory neurons that modulate cutaneous sensory pathways during locomotion in a simple vertebrate. J. Neurosci. 22, 10924-10934.

Li, W. C., Soffe, S. R., and Roberts, A. (2003). The spinal interneurons and properties of glutamatergic synapses in a primitive vertebrate cutaneous flexion reflex. J. Neurosci. 23, 9068-9077.

Li, W.C., Soffe, S. R., Wolf, E., and Roberts, A. (2006). Persistent responses to brief stimuli: feedback excitation among brainstem neurons. J. Neurosci. 26, 4026-4035.

Liao, J.C., and Fetcho, J. R. (2008). Shared versus specialized glycinergic spinal interneurons in axial motor circuits of larval zebrafish. J. Neurosci. 28, 12982-12992.

Lieske, S. P., Thoby-Brisson, M., Telgkamp, P., and Ramirez, J. M. (2000). Reconfiguration of the neural network controlling multiple breathing patterns: eupnea, sighs and gasps. Nat. Neurosci. 3, 600-607.

Liu, K. S., and Fetcho, J. R. (1999). Laser ablations reveal functional relationships of segmental hindbrain neurons in zebrafish. Neuron 23, 325-335.

Lundberg,A. (1979). Multisensory control of spinal reflex pathways. Prog. Brain Res. 50, 11-28.

Marder, E. (2000). Motor pattern generation. Curr. Opin. Neurobiol. 10, 691-698.

Marder, E., and Bucher, D. (2001). Central pattern generators and the control of rhythmic movements. Curr. Biol. 11, R986-R996.

Marder, E., Bucher, D., Schulz, D. J., and Taylor, A. L. (2005). Invertebrate central pattern generation moves along. Curr. Biol. 15, R685-R699.

Marder, E., and Calabrese, R. L. (1996). Principles of rhythmic motor pattern generation. Physiol. Rev. 76, 687-717.

McDearmid, J.R., and Drapeau, P. (2006). Rhythmic motor activity evoked by NMDA in the spinal zebrafish larva. J. Neurophysiol. 95, 401-417.

McLean, D. L., Fan, J., Higashijima, S., Hale, M. E., and Fetcho, J. R. (2007).
A topographic map of recruitment in spinal cord. Nature 446, 71-75.

McLean, D. L., Masino, M. A., Koh, I. Y., Lindquist, W. B., and Fetcho, J. R. (2008). Continuous shifts in the active set of spinal interneurons during changes in locomotor speed. Nat. Neurosci. 11, 1419-1429.

Metcalfe, W. K., Mendelson, B., and Kimmel, C. B. (1986). Segmental homologies among reticulospinal neurons in the hindbrain of the zebrafish larva. J. Comp. Neurol. 251, 147-159.

Mortin, L. I., Keifer,J., and Stein, P.S. (1985). Three forms of the scratch reflex in the spinal turtle: movement analyses. $J$. Neurophysiol. 53, 1501-1516.

Mortin, L. I., and Stein, P. S. (1989). Spinal cord segments containing key elements of the central pattern generators for three forms of scratch reflex in the turtle. J. Neurosci. 9, 2285-2296.

Mortin, L. I., and Stein, P. S. (1990). Cutaneous dermatomes for initiation of three forms of the scratch reflex in the spinal turtle. J. Comp. Neurol. 295, 515-529.

Morton, D. W., and Chiel, H. J. (1994). Neural architectures for adaptive behavior. Trends Neurosci. 17, 413-420.

Muller, U. K., and van Leeuwen, J. L. (2004). Swimming of larval zebrafish: ontogeny of body waves and implications for locomotory development. J. Exp. Biol. 207, 853-868.

Nieuwkoop, P. D., and Faber, J. (1956). Normal tables of Xenopus laevis (Daudin). Amsterdam: NorthHolland.

Oku, Y., Tanaka, I., and Ezure, K. (1994). Activity of bulbar respiratory neurons during fictive coughing and swallowing in the decerebrate cat. J. Physiol. (Lond.) 480, 309-324.

O'Malley, D. M., Kao, Y. H., and Fetcho, J. R. (1996). Imaging the functional organization of zebrafish hindbrain segments during escape behaviors. Neuron 17, 1145-1155.

Paton, G. (1846). On the perceptive power of the spinal chord, as manifested by cold-blooded animals. Edin- burgh Med. Surg. 65, 251-269.

Pearson, K. G. (1993). Common principles of motor control in vertebrates and invertebrates. Annu. Rev. Neurosci. 16, 265-297.

Perrins, R., Walford, A., and Roberts, A. (2002). Sensory activation and role of inhibitory reticulospinal neurons that stop swimming in hatchling frog tadpoles. J. Neurosci. 22, 4229-4240.

Pratt, C. A., and Jordan, L. M. (1987). Ia inhibitory interneurons and Renshaw cells as contributors to the spinal mechanisms of fictive locomotion. J. Neurophysiol. 57, 56-71.
Ritter, D. A., Bhatt, D. H., and Fetcho, J. R. (2001). In vivo imaging of zebrafish reveals differences in the spinal networks for escape and swimming movements. J. Neurosci. 21, 8956-8965.

Roberts, A. (2000). Early functional organization of spinal neurons in developing lower vertebrates. Brain Res. Bull. 53, 585-593.

Roberts, A., and Clarke, J. D. W. (1982). The neuroanatomy of an amphibian embryo spinal cord. Philos. Trans. R. Soc. Lond., B, Biol. Sci. 296, 195-212.

Roberts, A., Li, W., and Soffe, S. R. (2010). How neurons generate behaviour in a hatchling amphibian tadpole: an outline. Front. Behav. Neurosci. 4:16. doi:10.3389/fnbeh.2010.00016.

Roberts, A., and Sillar, K. T. (1990). Characterization and function of spinal excitatory interneurons with commissural projections in Xenopus laevis embryos. Eur. J. Neurosci. 2, 1051-1062.

Roberts, A., Walford, A., Soffe, S. R., and Yoshida, M. (1999). Motoneurons of the axial swimming muscles in hatchling Xenopus tadpoles: features, distribution, and central synapses. J. Comp. Neurol. 411, 472-486.

Robertson, G. A., Mortin, L. I., Keifer, J., and Stein, P. S. (1985). Three forms of the scratch reflex in the spinal turtle: central generation of motor patterns. J. Neurophysiol. 53, 1517-1534.

Saint-Amant, L., and Drapeau, P. (1998). Time course of the development of motor behaviors in the zebrafish embryo. J. Neurobiol. 37, 622-632.

Satou, C., Kimura, Y., Kohashi, T., Horikawa, K., Takeda, H., Oda, Y., and Higashijima, S. (2009). Functional role of a specialized class of spinal commissural inhibitory neurons during fast escapes in zebrafish. J. Neurosci. 29, 6780-6793.

Sherrington, C. S. (1906a). Observations on the scratch-reflex in the spinal dog. J. Physiol. (Lond.) 34, 1-50.

Sherrington, C. S. (1906b). The Integrative Action of the Nervous System. New York: Charles Scribner's Sons.

Sherrington, C. S. (1910a). Flexion-reflex of the limb, crossed extension reflex, and reflex stepping and standing. $J$. Physiol. (Lond.) 40, 28-121.

Sherrington, C. S. (1910b). Notes on the scratch-reflex of the cat. Q. J. Exp. Physiol. 3, 213-220.

Shiba, K., Nakazawa, K., Ono, K., and Umezaki, T. (2007). Multifunctional laryngeal premotor neurons: their activities during breathing, coughing, sneezing, and swallowing. J. Neurosci. 27, 5156-5162.

Soffe, S. R. (1991). Triggering and gating of motor responses by sensory stimulation: behavioural selection in 
Xenopus embryos. Proc. R. Soc. Lond., B, Biol. Sci. 246, 197-203.

Soffe, S. R. (1992). “To flex, swim or struggle? Behavioural selection in Xenopus embryos," in Neurobiology of Motor Programme Selection, J. Kien, C. R. McCrohan, and W. Winlow (Oxford: Pergamon Press), 73-87.

Soffe, S. R. (1993). Two distinct rhythmic motor patterns are driven by common premotor and motor neurons in a simple vertebrate spinal cord. J. Neurosci. 13, 4456-4469.

Soffe, S. R. (1996). Motor patterns for two distinct rhythmic behaviors evoked by excitatory amino acid agonists in the Xenopus embryo spinal cord. J. Neurophysiol. 75, 1815-1825.

Soffe, S. R., Clarke, J. D. W., and Roberts, A. (1984).Activity of commissural interneurons in spinal cord of Xenopus embryos. J. Neurophysiol. 51, 1257-1267.

Soffe, S. R., Roberts, A., and Li, W. C. (2009). Defining the excitatory neurons that drive the locomotor rhythm in a simple vertebrate: insights into the origin of reticulospinal control. J. Physiol. (Lond.) 587, 4829-4844.
Stein, P.S. (2005). Neuronal control of turtle hindlimb motor rhythms. J. Comp. Physiol. A 191, 213-229.

Stein, P. S., Camp, A. W., Robertson, G. A., and Mortin, L. I. (1986). Blends of rostral and caudal scratch reflex motor patterns elicited by simultaneous stimulation of two sites in the spinal turtle. J. Neurosci. 6, 2259-2266.

Stein, P. S., and Daniels-McQueen, S. (2003). Timing of knee-related spinal neurons during fictive rostral scratching in the turtle. J. Neurophysiol. 90, 3585-3593.

Stein, P. S. G., and Grossman, M. L. (1980). Central program for scratch reflex in turtle. J. Comp. Physiol. 140, 287-294.

Stein, P. S. G., Robertson, G. A., Keifer, J., Grossman, M. L., Berenbeim, J. A., and Lennard, P. R. (1982). Motor neuron synaptic potentials during fictive scratch reflex in turtle. J. Comp. Physiol. 146, 401-409.

Svoboda, K. R., and Fetcho, J. R. (1996). Interactions between the neural networks for escape and swimming in goldfish. J. Neurosci. 16, 843-852.
Thorsen, D. H., Cassidy, J. J., and Hale, M. E. (2004). Swimming of larval zebrafish: fin-axis coordination and implications for function and neural control. J. Exp. Biol. 207, 4175-4183.

Tinbergen, N. (1951). The Study of Instinct. Oxford: Clarendon Press.

Valk-Fai, T., and Crowe, A. (1978). Analyses of reflex movements in the hind limbs of the terrapin Pseudemys scripta elegans. J. Comp. Physiol. 125, 351-357.

Wyart, C., Del Bene, F., Warp, E., Scott, E. K., Trauner, D., Baier, H., and Isacoff, E. Y. (2009). Optogenetic dissection of a behavioural module in the vertebrate spinal cord. Nature 461, 407-410.

Zelenin, P.V.(2005).Activity of individual reticulospinal neurons during different forms of locomotion in the lamprey. Eur. J. Neurosci. 22, 2271-2282.

Zhao, F. Y., Burton, B. G., Wolf, E., and Roberts, A. (1998). Asymmetries in sensory pathways from skin to motoneurons on each side of the body determine the direction of an avoidance response in hatchling
Xenopus tadpoles. J. Physiol. (Lond.) 506, 471-487.

Conflict of Interest Statement: The authors declare that the research was conducted in the absence of any commercial or financial relationships that could be construed as a potential conflict of interest.

Received: 21 April 2010; paper pending published: 09 May 2010; accepted: 31 May 2010; published online: 28 June 2010.

Citation: Berkowitz A, Roberts $A$ and Soffe SR (2010) Roles for multifunctional and specialized spinal interneurons during motor pattern generation in tadpoles, zebrafish larvae, and turtles. Front. Behav. Neurosci. 4:36. doi: 10.3389/ fnbeh.2010.00036

Copyright (c) 2010 Berkowitz, Roberts and Soffe. This is an open-access article subject to an exclusive license agreement between the authors and the Frontiers Research Foundation, which permits unrestricted use, distribution, and reproduction in any medium, provided the original authors and source are credited. 